\title{
Neuronal surface $P$ antigen (NSPA) modulates postsynaptic NMDAR stability through ubiquitination of tyrosine phosphatase PTPMEG
}

Sofía Espinoza 1,2, Sebastián B. Arredondo ${ }^{3}$, Francisca Barake ${ }^{1,2,4}$, Francisco Carvajal ${ }^{5,6}$, Fernanda G. Guerrero ${ }^{3}$, Fabian Segovia-Miranda², David M. Valenzuela7, Ursula Wyneken ${ }^{8}$, Alejandro Rojas-Fernández ${ }^{9}$, Waldo Cerpa ${ }^{2,5,6}$, Loreto Massardo ${ }^{1}$, Lorena Varela-Nallar ${ }^{3}$ and Alfonso González ${ }^{1,2,4^{*}}$ (i)

\begin{abstract}
Background: Cognitive dysfunction (CD) is common among patients with the autoimmune disease systemic lupus erythematosus (SLE). Anti-ribosomal P autoantibodies associate with this dysfunction and have neuropathogenic effects that are mediated by cross-reacting with neuronal surface P antigen (NSPA) protein. Elucidating the function of NSPA can then reveal CD pathogenic mechanisms and treatment opportunities. In the brain, NSPA somehow contributes to glutamatergic NMDA receptor (NMDAR) activity in synaptic plasticity and memory. Here we analyze the consequences of NSPA absence in KO mice considering its structural features shared with E3 ubiquitin ligases and the crucial role of ubiquitination in synaptic plasticity.

Results: Electrophysiological studies revealed a decreased long-term potentiation in CA3-CA1 and medial perforant pathway-dentate gyrus (MPP-DG) hippocampal circuits, reflecting glutamatergic synaptic plasticity impairment in NSPA-KO mice. The hippocampal dentate gyrus of these mice showed a lower number of Arc-positive cells indicative of decreased synaptic activity and also showed proliferation defects of neural progenitors underlying less adult neurogenesis. All this translates into poor spatial and recognition memory when NSPA is absent. A cell-based assay demonstrated ubiquitination of NSPA as a property of RBR-type E3 ligases, while biochemical analysis of synaptic regions disclosed the tyrosine phosphatase PTPMEG as a potential substrate. Mice lacking NSPA have increased levels of PTPMEG due to its reduced ubiquitination and proteasomal degradation, which correlated with lower levels of GluN2A and GluN2B NMDAR subunits only at postsynaptic densities (PSDs), indicating selective trafficking of these proteins out of PSDs. As both GluN2A and GluN2B interact with PTPMEG, tyrosine (Tyr) dephosphorylation likely drives their endocytic removal from the PSD. Actually, immunoblot analysis showed reduced phosphorylation of the GluN2B endocytic signal Tyr1472 in NSPA-KO mice.

(Continued on next page)
\end{abstract}

\footnotetext{
* Correspondence: agonzara@uss.cl

'Centro de Biología Celular y Biomedicina (CEBICEM), Facultad de Medicina y Ciencia, Universidad San Sebastián, 7510157 Santiago, Chile

${ }^{2}$ Centro de Envejecimiento y Regeneración (CARE), Facultad de Ciencias Biológicas, Pontificia Universidad Católica de Chile, 8330025 Santiago, Chile

Full list of author information is available at the end of the article
}

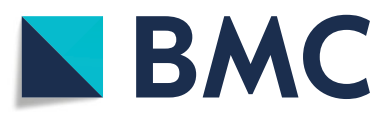

(c) The Author(s). 2020 Open Access This article is licensed under a Creative Commons Attribution 4.0 International License, which permits use, sharing, adaptation, distribution and reproduction in any medium or format, as long as you give appropriate credit to the original author(s) and the source, provide a link to the Creative Commons licence, and indicate if changes were made. The images or other third party material in this article are included in the article's Creative Commons licence, unless indicated otherwise in a credit line to the material. If material is not included in the article's Creative Commons licence and your intended use is not permitted by statutory regulation or exceeds the permitted use, you will need to obtain permission directly from the copyright holder. To view a copy of this licence, visit http://creativecommons.org/licenses/by/4.0/ The Creative Commons Public Domain Dedication waiver (http://creativecommons.org/publicdomain/zero/1.0/) applies to the data made available in this article, unless otherwise stated in a credit line to the data. 


\begin{abstract}
(Continued from previous page)
Conclusions: NSPA contributes to hippocampal plasticity and memory processes ensuring appropriate levels of adult neurogenesis and PSD-located NMDAR. PTPMEG qualifies as NSPA ubiquitination substrate that regulates Tyr phosphorylation-dependent NMDAR stability at PSDs. The NSPA/PTPMEG pathway emerges as a new regulator of glutamatergic transmission and plasticity and may provide mechanistic clues and therapeutic opportunities for antiP-mediated pathogenicity in SLE, a still unmet need.
\end{abstract}

Keywords: NMDA receptor, GluN2B Tyr1472, Tyrosine phosphatase PTPMEG/PTPN4, Synaptic plasticity, Memory, Postsynaptic densities, Ubiquitination, NSPA, ZZEF1, NPSLE

\section{Background}

Neuronal surface P antigen (NSPA) is a protein of unknown function originally discovered as a cross-reacting target of anti-ribosomal $\mathrm{P}$ protein autoantibodies (antiP) that associates with neuropsychiatric manifestations, particularly psychosis and cognitive dysfunction (CD), in patients with systemic lupus erythematosus (SLE) [1]. $\mathrm{CD}$ is common among neuropsychiatric SLE (NPSLE) manifestations, affecting up to $80 \%$ of SLE patients [2]; it associates with a decreased quality of life [3] and has no targeted therapy at present [2]. Elucidating NSPA function in neurons can reveal mechanistic clues to better understand antibody-driven CD in NPSLE and could uncover new neuronal alterations leading to neuropsychiatric disease, from which more specific treatments might emerge.

Processes of learning and memory-encoding are possible thanks to synaptic plasticity that either strengthens or weakens synapses, as reflected in long-term potentiation (LTP) or long-term depression (LTD), respectively [4]. Mostly studied in the hippocampus, LTP and LTD are initiated by the activation of $N$-methyl-D-aspartate receptor (NMDAR) that results in long lasting increases or decreases in the function of $\alpha$-amino-3-hydroxy-5methyl-4-isoxazolepropionic acid receptor (AMPAR) [4]. AMPAR and NMDAR are ionotropic glutamatergic receptors highly enriched in the hippocampus and widely expressed in other areas of the brain participating in memory, emotion, and behavior [5, 6]. NMDAR receptors are conformed by two obligatory GluN1 subunits combined with two GluN2 (A, B, C, or D) or GluN3 (A and $\mathrm{B})$ subunits, while AMPAR are composed of various combinations of four subunits (GluA1-GluA4) [7, 8]. The abundance of NMDAR and AMPAR at the postsynaptic density (PSD) crucial for LTP and LTD depends on their in-out diffusion and trafficking along endocytic routes, which are mainly controlled by phosphorylation modifications through yet little understood mechanisms $[9,10]$. In different forms of synaptic plasticity, the role of glutamatergic receptors can be regulated by tyrosine phosphatases such as striatal-enriched protein tyrosine phosphatase (STEP), and the megakaryocyte protein tyrosine phosphatase (PTPMEG; also known as PTPN4)
[11-15]. STEP has been shown to regulate Tyr dephosphorylation of NMDAR and AMPAR during LTP in the hippocampus [11, 15], while PTPMEG participates in synaptic plasticity associated with Tyr dephosphorylation of GluA2 during LTD in the cerebellum [13, 14]. Even though PTPMEG has been found to interact with GluN2 NMDAR subunits and to be present at the PSD [12], its role in the hippocampus remains unknown. Hippocampal memory processes also depend on neurogenesis involving proliferation, survival and differentiation of adult neural stem/progenitor cells (NPCs) [16]. Newly integrated neurons may participate in hippocampal functions that not only include learning and memory but also social behavior, anxiety, and stress regulation [17].

In NPSLE, anti-P antibodies originally described in patients with lupus psychosis have been found more recently to be associated with $\mathrm{CD}$ [1]. In vitro, anti-P antibodies induce calcium influx leading to apoptosis in neurons [18-20] and alter CA3-CA1 glutamatergic transmission and synaptic plasticity affecting the activity of AMPAR and NMDAR in hippocampal slices [20]. In vivo, anti-P antibodies injected into the cortex or hippocampus induce neuronal apoptosis very likely through glutamatergic excitotoxicity $[18,19]$. However, a single injection of anti-P antibodies into the circulation accompanied by disruption of the blood brain barrier (BBB) impairs hippocampal-dependent spatial memory reflecting alterations in glutamatergic plasticity without enhancing apoptosis [19]. Therefore, anti-P antibodies may induce glutamatergic synaptic dysfunction accompanied or not by apoptosis likely depending on their concentration in the brain.

NSPA as target of anti-P antibodies and NMDAR as target of a subset of anti-dsDNA antibodies are currently considered essential mediators of antibody-driven $C D$ in SLE patients [1, 2, 21-23]. So far, NSPA is the only recognized protein that mediates neuropathogenic effects of anti-P antibodies in NPSLE $[1,2,20]$. However, in contrast with the well-known function of ionotropic glutamatergic receptors and how they are affected as antibody targets [1, 21, 24, 25], the neuronal role of NSPA remains little understood. NSPA is a membrane protein that exposes a $\mathrm{P}$-epitope to the cell surface and 
is expressed in neurons at regions involved in emotion, memory, and cognition [18]. NSPA is encoded by the unique Zzef1 gene encompassing 2924 residues that include an anaphase promoter complex 10 (APC10) and two ZZ-type zinc finger domains [20]. These structural characteristics strongly point to NSPA as an E3 ubiquitin ligase [20]. The APC10 domain has only been described in E3 ubiquitin ligases [26], and even though the ZZ-type finger domains can be found in other proteins, it is also an important component of certain E3 ligases [27]. Protein ubiquitination catalyzed by E3 ligases is crucial in the regulation of AMPAR and NMDAR and consequently modulates glutamatergic synaptic transmission and plasticity [28]. Our previous studies approaching the function of NSPA characterized a knockin mice that express a truncated NSPA (NSPA ${ }^{\text {tr/tr }}$, here called NSPA-TR) lacking the APC10 domain [20]. These NSPA-TR mice have alterations in glutamatergic plasticity reflected in impaired hippocampal LTP and poor performance in memory tests [20]. Interestingly, NSPATR mice have a decreased NMDAR-mediated transmission in the CA3-CA1 hippocampal circuit [20]. Therefore, NSPA seems to be required for NMDAR function and synaptic plasticity in memory [20]. NSPA function may hide unexpected aspects of glutamatergic synapse regulation and memory processes. It is thus important to first assess the effect of NSPA silencing, as unnoticed effects of truncated NSPA cannot be discarded. If the NSPA-TR phenotype is reproduced in NSPA knockout (NSPA-KO) mice, the unknown mechanism(s) linking NSPA to NMDAR function may be further explored. It is also interesting to define whether NSPA is required for other processes involved in memory, such as adult neurogenesis [29].

In this work, we used NSPA-KO mice and found that NSPA is not only involved in glutamatergic transmission and synaptic plasticity but also in adult neurogenesis. We also provide evidence pointing to NSPA as an E3 ubiquitin ligase and PTPMEG as one of its potential substrates. Furthermore, our results show that PTPMEG is degraded by the ubiquitin-proteasome system (UPS) impacting upon Tyr phosphorylation and PSD expression levels of NMDAR. Hippocampal PSDs of NSPA-KO mice have decreased levels of GluN2A and GluN2B, both NMDAR subunits that interact with PTPMEG. We propose that NSPA at the plasma membrane and downstream cytosolic PTPMEG constitutes a novel ubiquitinbased regulation system that contributes to synaptic plasticity and memory as determinants of NMDAR location at PSDs.

\section{Results}

To understand the mechanism that involves NSPA with NMDAR function, we first performed experiments in mice lacking NSPA expression (NSPA-KO), aimed at discarding a previously unnoticed deleterious action of truncated NSPA on glutamatergic transmission. The results led us to also consider the role of NSPA in hippocampal adult neurogenesis, another process involved in memory [29], which is also sensitive to synaptic activity and plasticity [30]. Then, we used a heterologous system to test whether NSPA becomes ubiquitinated, as required for certain types of E3 ubiquitin ligases, and made biochemical analysis in the hippocampus to search for NSPA-regulated proteins. In particular, we focused on PTPMEG as a potential ubiquitination substrate that might regulate postsynaptic NMDAR levels through Tyr dephosphorylation.

\section{NSPA knockout (NSPA-KO) mice}

Previous work showed that NSPA knock-in (NSPA-TR) mice expressing a truncated form of NSPA, which lacks the APC10 domain, perform poorly in the Morris water maze and memory flexibility tests and have depressed NMDAR-transmission and impaired LTP [20]. To discard that the truncated version of NSPA might act in a way unrelated to the native NSPA, we re-evaluated the NSPA phenotype in the hippocampus of knockout mice lacking any expression of NSPA.

NSPA full knockout mouse (Zzef1 ${ }^{\text {tm2.1(KOMP)vlcg }}$ ) have 55 exons of the NSPA-encoding gene Zzef1 replaced with a $L a c Z$ cassette, where $\beta$-gal staining reflects the activity of NSPA promoter. The $\beta$-gal staining pattern of NSPA-KO mice reproduced the pattern described in NSPA-TR mice [20]. In the hippocampus, NSPA is expressed in CA1, dentate gyrus, and ventral but not dorsal CA3 (Additional file 1: Fig. S1a). Reverse transcriptase-PCR using three primer pairs for different exons (Additional file 1: Fig. S1b) that detects NSPA mRNA in the hippocampus of wild type (NSPA-WT) showed absence of NSPA mRNA in the NSPA-KO mice (Additional file 1: Fig. S1c). Immunoblots with commercial anti-ZZEF1 and our anti-APC10 antibodies [20] could not detect NSPA protein in NSPA-KO mice (Additional file 1: Fig. S1c). These results corroborate the lack of NSPA expression in NSPA-KO mice.

\section{Impaired synaptic plasticity, neurogenesis and hippocampus-dependent memory in NSPA-KO mice} NSPA-TR mice have impaired NMDAR-mediated neurotransmission without alterations in AMPAR-mediated transmission, nevertheless resulting in decreased synaptic plasticity of CA3-CA1 synapses [20]. Here, we expanded the LTP assays registering fEPSP not only in the Schaffer collateral-CA1 pathway (CA3-CA1 synapses), as before [20], but also in the medial perforant pathway synapses on dentate gyrus (DG) granule cells (MPP-DG synapses), which also express NSPA [20]. 
Similar to NSPA-TR mice [20], NSPA-KO mice showed decreased LTP in CA3-CA1 (Fig. 1a). Paired pulse facilitation assay discarded a presynaptic contribution (Fig. 1b). The MPP-DG synapses of NSPA-KO mice also showed decreased LTP (Fig. 1c) with unaltered presynaptic function (Fig. 1d). These results reinforce our previous proposal that NSPA plays a role in glutamatergic synaptic plasticity, here disclosed in two different hippocampal circuits related with memory [31].

To test whether NSPA is required for basal neuronal activity, we assessed the expression of Arc protein, an immediate-early gene product specifically targeted to regions of dendrites that receive direct synaptic stimulation [32]. Arc expression correlates with synaptic activity in glutamatergic neurons [33], increasing as a requirement for LTP and long-term memory consolidation [34, 35]. We found a decreased number of Arc-positive cells in the granule cell layer (GCL) of the NSPA-KO DG (Fig. 1e), compared with NSPAWT mice. This indicates less DG neuronal activity in congruency with the decreased LTP observed in the MPP-DG synapses of NSPA-KO mice.

\section{A. HFS-LTP in CA3-CA1}

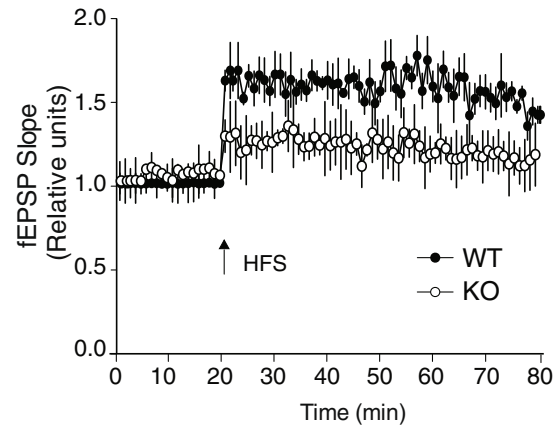

C. HFS-LTP in MPP-DG

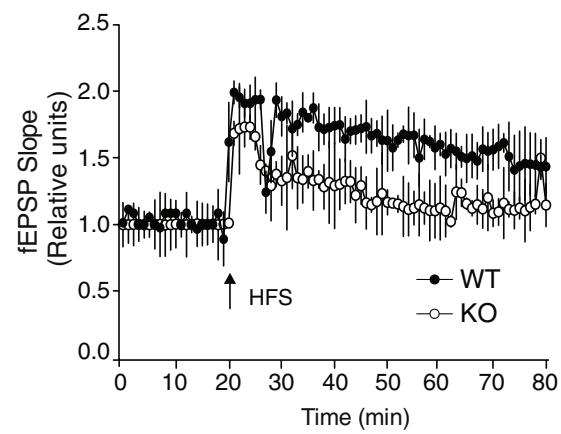

E.

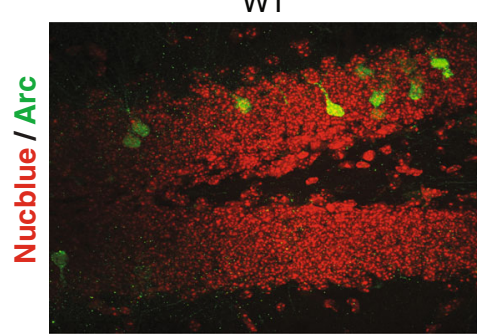

Last $10 \mathrm{~min}$

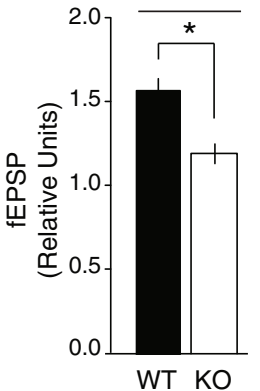

Last $10 \mathrm{~min}$

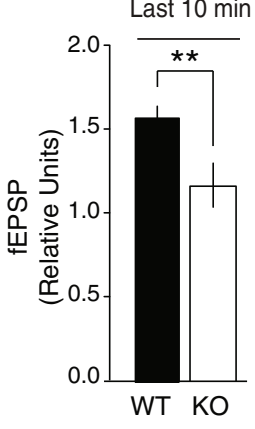

\section{B. PPF in CA3-CA1}

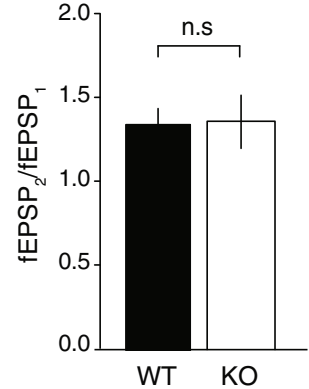

D. PPF in MPP-DG

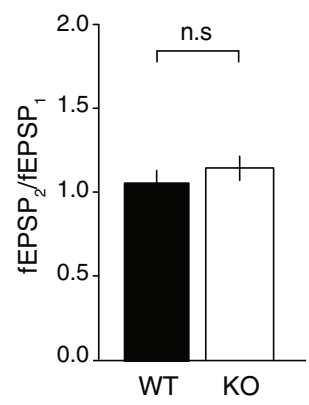

$\mathrm{KO}$
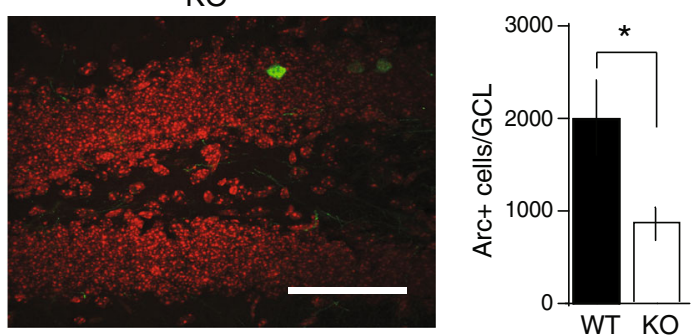

Fig. 1 Impaired long-term potentiation (LTP) in CA1 and dentate gyrus (DG) regions of NSPA-KO mice. a LTP generated by high-frequency stimulation (HFS) in CA1 area shows a decreased fEPSP (quantified by slope and normalized by baseline) in NSPA-KO compared to WT mice. Graph corresponds to the last 10 min of recording (mean \pm SEM; $n=9$ slices; three animals per experimental group; ${ }^{*} P<0.05$ by $t$-test.). b Paired pulse facilitation (PPF) of fEPSP shows no alterations in presynaptic activity in CA3-CA1 synapses of NSPA-KO mice (mean \pm SEM; $n=7$ slices; $n$.S, non-statistical differences, $t$-test). c Decreased LTP in MPP-DG of NSPA-KO compared with WT mice. Graph corresponds to the last 10 min of recording (mean $\pm S E M ; n=9$ slices; three animals per experimental group; ${ }^{* *} P<0.01$ by $t$-test). $\mathbf{d}$ PPF indicates no alteration in presynaptic activity in MPP-DG synapses of NSPA-KO mice (mean \pm SEM; $n=7$ slices; $n . s$, non-statistical differences, $t$-test). e Immunofluorescence staining of $\operatorname{Arc}\left(\mathrm{ArC}^{+}\right)$shows less neurons expressing this marker of neuronal activity in the DG of NSPA-KO mice (mean \pm SEM; $n=3$ mice per experimental group; ${ }^{*} P<0.05$, $t$-test; Scale bar: $\left.50 \mu \mathrm{m}\right)$. Source data values are included in Additional file 2 
Adult hippocampal neurogenesis is regulated by DG neuronal activity and is involved in the hippocampal plasticity required for spatial learning, cognitive flexibility, object recognition and memory [29, 36, 37]. In the hippocampus, adult neurogenesis is restricted to the DG, where new neurons are generated from radial glia-like neural stem cells located within the subgranular zone (SGZ). After activation, these neural stem cells give rise to highly proliferative neural progenitor cells (NPCs), which then differentiate into immature neurons and subsequently to mature granule cells [16]. Induction of LTP in MPP-DG synapses promotes proliferation of NPCs and survival of adult-born neurons in an NMDARdependent manner $[30,38]$. This process can be evaluated detecting doublecortin (DCX), which is expressed in newly generated neuroblasts and immature neurons [36]. We observed a decrease in DCX-positive cells in the DG of 2-month-old NSPA-KO compared with NSPA-WT mice (Fig. 2a), indicating a reduction in neurogenesis. To evaluate whether this reduction was due to a reduced proliferation, we assessed the mitotic marker Ki67. NSPA-KO mice showed a significant decrease in the total number of Ki67-positive cells in the SGZ compared to NSPA-WT mice (Fig. 2b). This indicates a reduced proliferation of hippocampal NPCs in the absence of NSPA. Then, to evaluate neuronal differentiation, mice received a daily dose of $100 \mathrm{mg} / \mathrm{kg} \mathrm{BrdU}$ for 3 days and were euthanized 2 weeks later (Fig. 2c). We found a reduced total number of BrdU-positive cells in the granular cell layer (GCL) of the DG in NSPA-KO mice compared to that in NSPA-WT mice (Fig. 2c), without changes in the percentage of BrdU-positive cells expressing DCX (Fig. 2d). Altogether, these results indicate that NSPA-KO mice have decreased proliferation of NPCs, but unaffected differentiation of newborn cells into neurons.

Hippocampal LTP and adult neurogenesis are crucial in learning and memory $[6,29]$. We tested locomotion, exploration, and anxiety reflecting general brain function and two behavioral tests that involve hippocampal memory function. The open field (OF) test that measures locomotion and anxiety-like behaviors [39] showed no alterations in NSPA-KO mice as measured by the total distance moved and similar amount of time spent in the center region of the OF arena compared with NSPAWT mice (Fig. 3a). Hence, NSPA-KO mice have normal locomotion activity and no anxiety-like behavior. Then, we evaluated novel object recognition (NOR) memory [40] and found that NSPA-KO mice exhibit decreased preference for the novel object compared with NSPAWT mice (Fig. 3b). Finally, a modified spatial memory paradigm task that evaluates episodic-like memory (memory flexibility) [41] showed poor performance of NSPA-KO mice (Fig. 3c), not due to vision capability problems (Fig. 3d). Therefore, NSPA-KO mice have impaired hippocampal-dependent memory, without anxiety-like behaviors or altered locomotion activity.

\section{NSPA as E3 ubiquitin ligase}

Ubiquitination is an important posttranslational modification involved in the regulation of glutamatergic transmission and synaptic plasticity [28]. NSPA has an APC10 domain exclusively found in E3 ubiquitin ligases and also contains two ZZ-type zinc finger domains that are included in some of these enzymes [20, 42] (Fig. 4a). NSPA ZZ-type domains have a cystein-rich pattern similar to the consensus pattern of the BRcat (also called IBR) domains found in RBR-type E3 ligases like Cullin9/ Parc (Fig. 4b) and Parkin [42]. NSPA is then more closely related to RBR-type E3 ligases, which characteristically are first auto-ubiquitinated to then transfer the ubiquitin to their substrates [43]. We tested this possibility by assessing whether NSPA becomes ubiquitinated in a cell-based ubiquitination assay. HEK293 cells cotransfected with NSPA and myc-6xHis-Ub expression plasmids clearly showed ubiquitin-NSPA complexes, as detected by Ni-NTA affinity purification in strong denaturing conditions (Fig. 4c). Therefore, NSPA seems to be an E3 ubiquitin ligase with characteristics of RBRtype E3 enzymes [42]. Considering this posssibility, the altered synaptic plasticity of NSPA-KO mice might be due to abnormal levels of synaptic proteins that are directly degraded by the UPS or indirectly dependent on this system, as addressed below.

\section{Decreased levels of GluN2A and GluN2B NMDAR subunits} in the hippocampal postsynaptic region of NSPA-KO mice Given the alterations in glutamatergic synaptic plasticity and memory in NSPA-KO mice and the possible role of NSPA as an E3 ubiquitin ligase, we evaluated the expression levels of hippocampal synaptic proteins. Immunoblot analyses of total hippocampal lysates showed no significant differences in synaptic receptors and scaffolding proteins between NSPA-WT and NSPA-KO mice (Fig. 5a). However, impaired LTP is most likely due to local alterations in synaptic proteins [6], and therefore, we isolated hippocampal synaptosomes and postsynaptic densities (PSDs) from both NSPA-WT and NSPA-KO mice. We verified the purity of isolated hippocampal PSDs by Western blot using the presynaptic marker VGlut1 and the postsynaptic marker PSD95 (Additional file 1: Fig. S2). Strikingly, we found a significant decrease of GluN2A and GluN2B subunits of NMDAR in NSPAKO compared with NSPA-WT mice, both in synaptosomes (Additional file 1: Fig. S3) and PSDs (Fig. 5b). The lower levels of GluN2A and GluN2B subunits detected just in synaptosomes and PSDs of NSPA-KO mice, while maintaining similar levels in total hippocampal 
A.

WT

KO
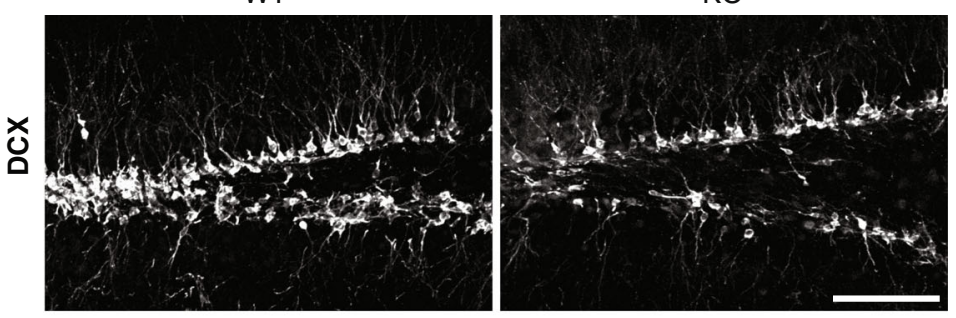

B.

WT

$\mathrm{KO}$
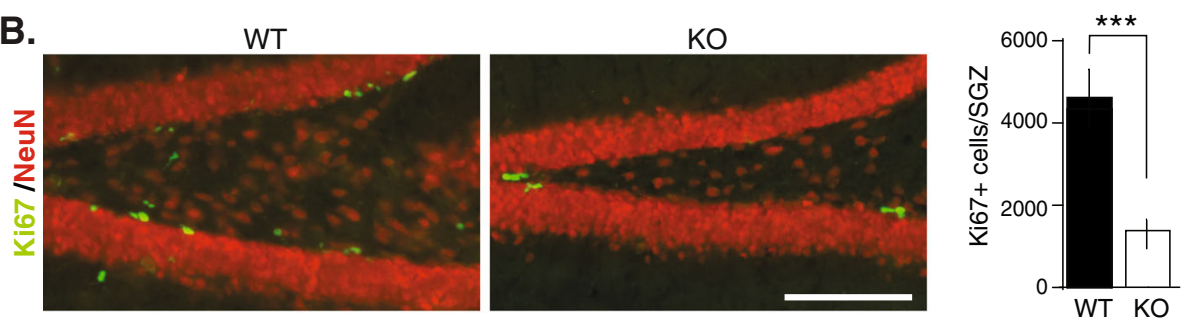

c.
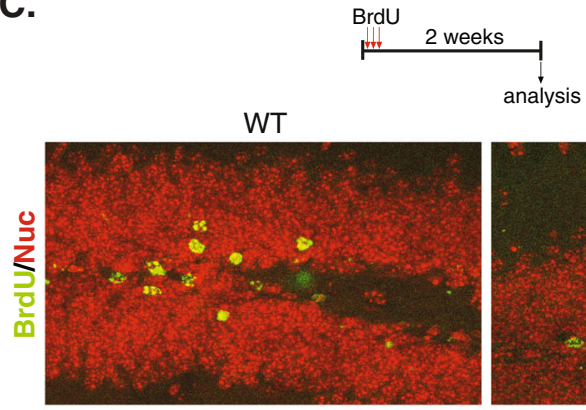

$\mathrm{KO}$
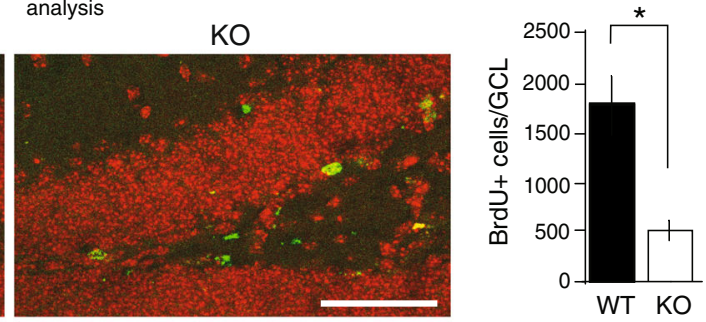

D.

WT

KO
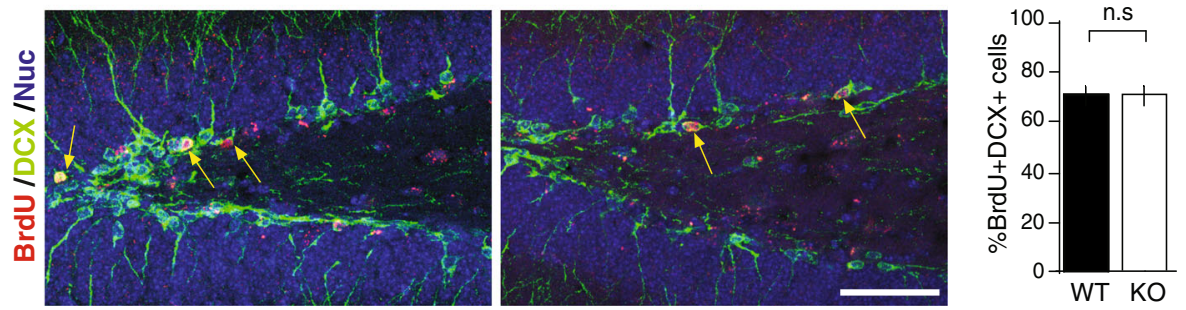

Fig. 2 Decreased proliferation of neural progenitors in the dentate gyrus (DG). NSPA-KO mice. a Representative immunostaining of DCX in the DG of WT and NSPA-KO mice. Scale bar: $100 \mu \mathrm{m}$. b Representative immunostaining of Ki67 and the mature neuronal marker NeuN in the DG of WT and NSPA-KO mice. Scale bar: $100 \mu \mathrm{m}$. Quantification of total number of Ki67+ cells in the SGZ. (mean \pm SEM; $n=10$ mice per condition; ${ }^{* * *} P<0.001, t$-test). $\mathbf{c}$ Schematic representation of the experimental procedure. Animals received a daily dose of $100 \mathrm{mg} \mathrm{kg}^{-1} \mathrm{BrdU}$ for 3 days and were sacrificed 2 weeks later. Immunostaining of BrdU in the DG of WT and NSPA-KO mice. Nuclei were stained with NucBlue (Nuc). Scale bar: $50 \mu \mathrm{m}$. Quantification of total number of BrdU+ cells in the granule cell layer (GCL) of the DG (mean \pm SEM; $n=4$ mice per condition; ${ }^{*} P<0.05$, Mann-Whitney test). $\mathbf{d}$ Representative immunostaining of BrdU and DCX. Scale bar: $20 \mu \mathrm{m}$. Quantification of the percentage of BrdU-positive cells expressing DCX (mean \pm SEM; $n=4$ mice per condition; n.s, non-statistical differences, Mann-Whitney test). Source data values are included in Additional file 2

homogenates, reflect changes in the localization of these receptors rather than global expression modifications. This is also congruent with the decreased NMDARdependent neurotransmission previously detected in NSPA-TR mice [20]. Other relevant synaptic proteins such as PSD95, GluA1, and GluA2 AMPAR subunits remained relatively unchanged, indicating specificity of NSPA-mediated regulation. Ubiquitination of NMDAR subunits has been described and might be related with degradation pathways [28]. However, NSPA does not seem to be involved in NMDAR ubiquitination; otherwise, higher and not lower levels of NMDAR would have been found at the PSD. A defect in the ubiquitination of an NSPA substrate that 


\section{A. Open-field}

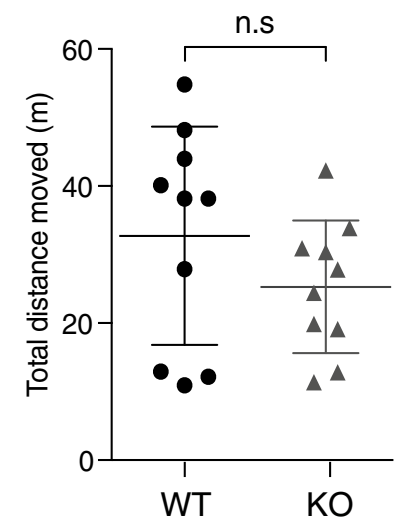

\section{B. Novel object recognition}

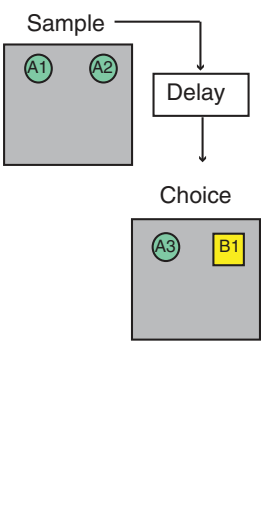

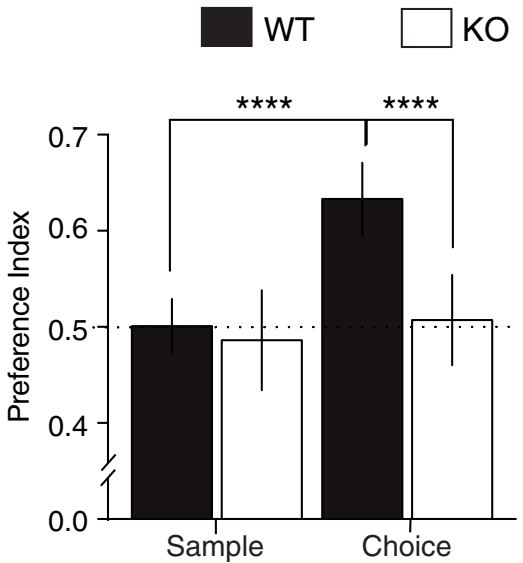

D. Visible Platform

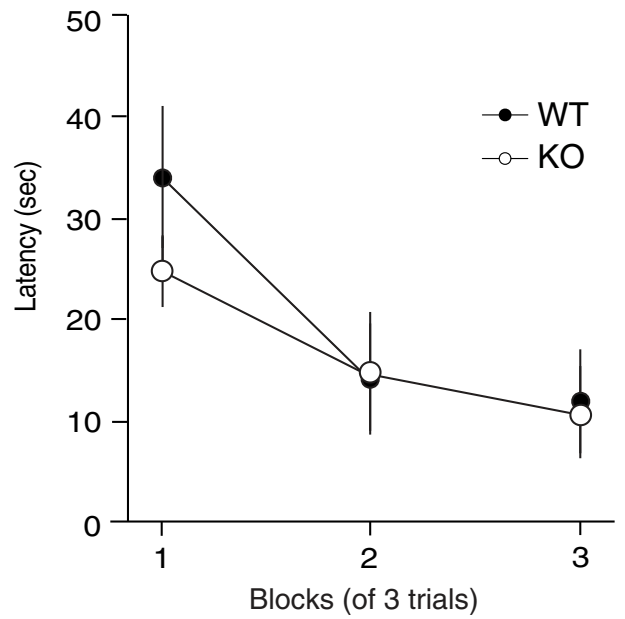

Fig. 3 NSPA-KO mice have impaired hippocampal-memory-dependent tasks. a Open field test (novel environment) shows that WT and NSPA-KO mice have similar locomotor activity, as measured by the total distance moved, and also spent similar time in the center region (mean \pm SEM; $n=10$ mice per group; n.s, non-statistical differences, $t$-test). b Novel recognition (NOR) task comprising sample (10 min), delay (4 h), and choice (10 min) phases. In the scheme, A1 and A2 represent identical objects and B1 is a novel object. Preference index is the time spent with object divided by total exploration time. WT mice preferentially explored the novel object whereas NSPA-KO mice spent similar times in each object (mean $\pm \mathrm{SEM} ; n=10$ mice per group; ${ }^{* * *} P<0.0001$ versus WT mice by one-way ANOVA, followed by Bonferroni post hoc test). c Memory flexibility test shows a higher number of trials required by NSPA-KO compared with WT mice to meet criterion (mean \pm SEM; $n=6$ mice per group; ${ }^{* *} P<0.001$ t-test). $\mathbf{d}$ Morris water maze test with visible platform indicates similar vision capability and general health of WT and NSPA-KO mice

selectively regulates the levels of GluN2A and GluN2B NMDAR subunits at the PSD might better explain these results.

\section{Decreased Tyr1472 phosphorylation of GluN2B subunit in NSPA-KO hippocampus}

NMDAR postsynaptic abundance is critically regulated by the phosphorylation of the cytoplasmic tails of GluN2A and GluN2B subunits, including Tyr phosphorylated residues [44]. For instance, phosphorylation of GluN2B subunit at
Tyr1472 (pTyr1472) prevents endocytosis and consequently enhances the stability and surface expression of NMDAR at the synaptic zone $[9,45]$. An antibody specific to pTyr1472 $[9,45,46]$ allowed us to assess the levels of GluN2B phosphorylated at this particular residue in hippocampal crude membrane fraction (P2), which we found decreased in NSPA-KO compared with NSPA-WT mice (Fig. 5c). Therefore, as reported in other conditions $[9,45,46]$, dephosphorylation of GluN2B Tyr1472 may account for the decreased levels of NMDAR bearing this subunit at the PSD. 


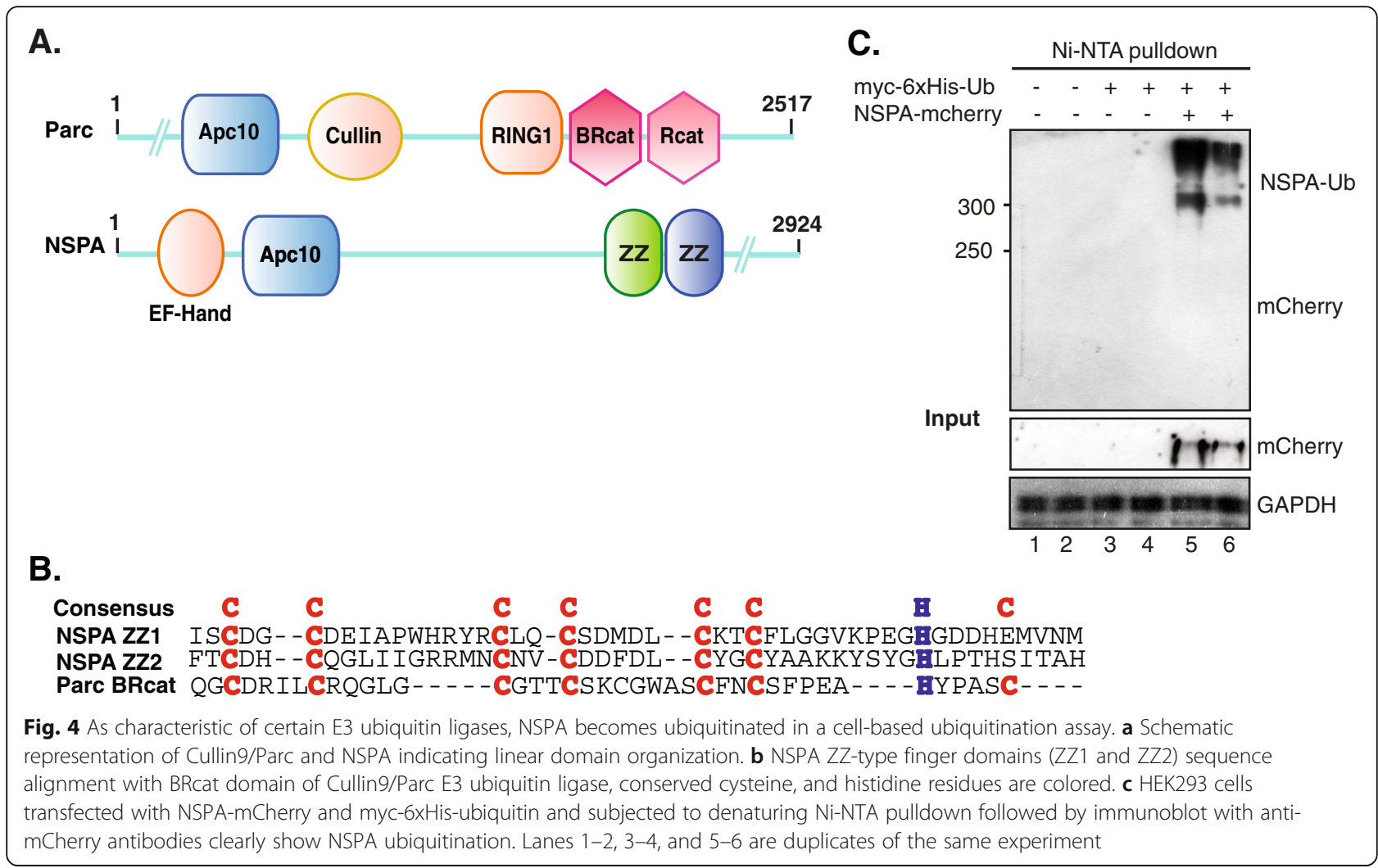

These results suggest that enzymes that regulate GluN2B Tyr1472 phosphorylation have altered activities in NSPA-KO mice, likely due to ubiquitinationdependent defects affecting their levels. STEP 61 is ubiquitinated by the E3 ligase Parkin [47], and its levels are UPS-controlled by degradation, impacting upon GluN2B Tyr1472 phosphorylation and NMDAR presence at the PSD $[46,48]$. However, immunoblots of NSPA-WT and NSPA-KO synaptosomal P2 fractions showed no differences in STEP 61 levels (Fig. 6a) and ubiquitination (Fig. 6b). We also evaluated tyrosine kinases of the Src family known to mediate tyrosine phosphorylation of GluN2 subunits, particularly Fyn that is the main subunit responsible for GluN2B Tyr1472 phosphorylation [49]. Neither Src (Additional file 1: Fig. S4) nor Fyn (Fig. 5c) showed level changes. Therefore, other enzymes distinct from STEP, Src and Fyn, would be involved in NSPA-dependent regulation of NMDAR Tyr phosphorylation.

\section{PTPMEG levels are increased due to impaired} ubiquitination and UPS-mediated degradation in NSPAKO hippocampus

PTPMEG is a Tyr phosphatase previously described to interact with GluN2 NMDAR subunits and to associate with the PSD, but its role in NMDAR Tyr phosphorylation remains unknown and even confusing [12]. We analyzed the levels of PTPMEG and also whether it is ubiquitinated and degraded by the UPS in an NSPAdependent manner. Interestingly, hippocampal P2 fractions of NSPA-KO mice not only showed increased PTPMEG expression levels compared with NSPA-WT mice but also that proteasomal inhibition shielded this difference (Fig. 6d). Immunoprecipitation from crude hippocampal membrane fractions followed by immunoblot against ubiquitin revealed less ubiquitinated PTPMEG in NSPA-KO compared with NSPA-WT mice (Fig. 6e). The NSPA-TR mice expressing a truncated form of NSPA, which lacks the APC10 domain and have similar alterations as NSPA-KO mice [20], also showed reduced ubiquitinated PTPMEG (Fig. 6e). These results indicate that NSPA controls PTPMEG levels through ubiquitination and UPS-mediated degradation in the hippocampus. In this scenario, the absence of NSPA leads to increased PTPMEG levels very likely accounting for the decreased phosphorylation of GluN2B at Tyr1472.

\section{PTPMEG interacts with GluN2A and GluN2B subunits}

Previous studies have described that PTPMEG interacts with the GluN2A and GluN2B subunits of NMDAR [12]. Accordingly, immunoprecipitation of PTPMEG from crude hippocampal P2 fraction of wild type mice followed by immunoblot against GluN2A and GluN2B 


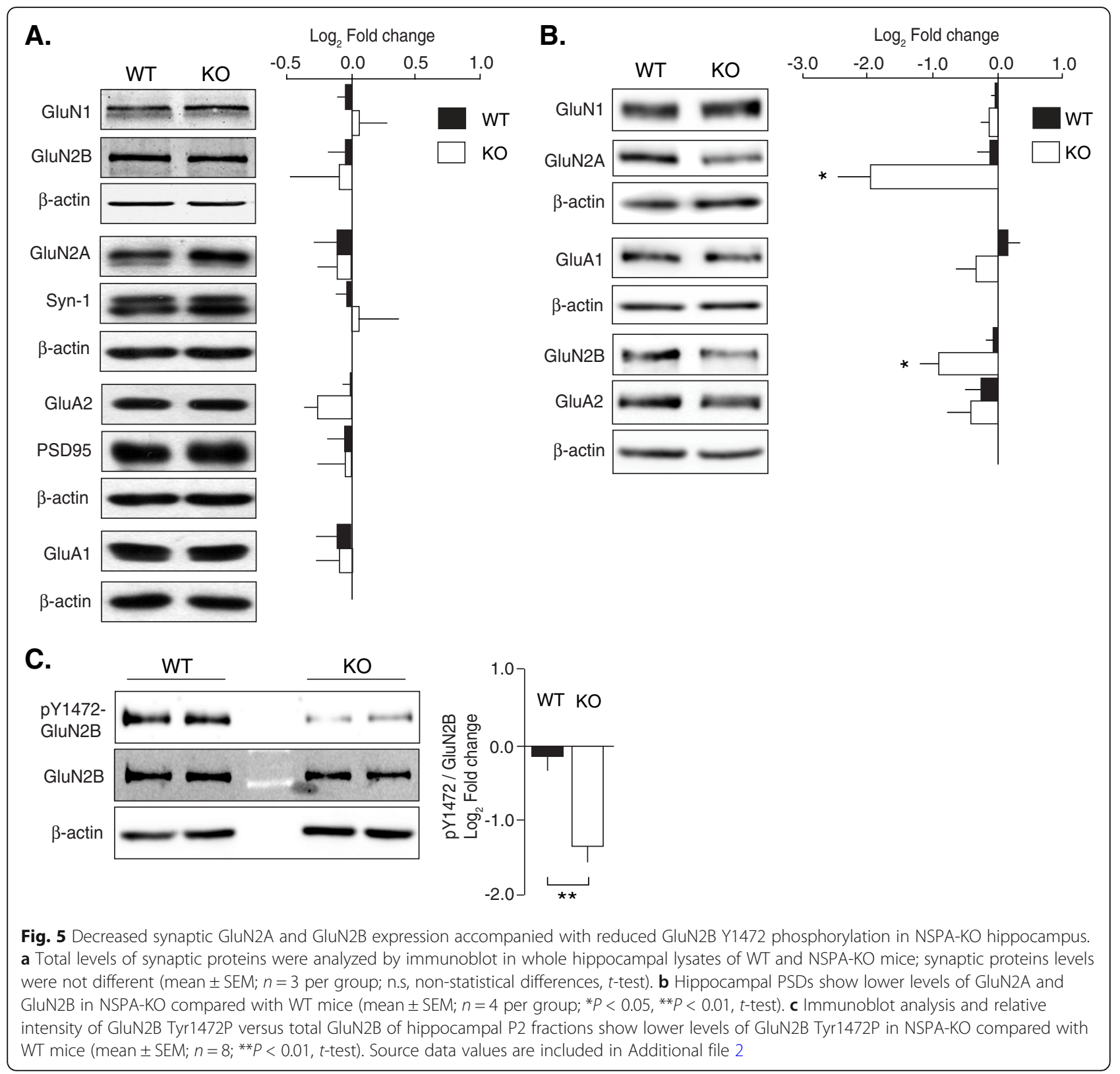

subunits revealed the presence of both NMDAR subunits in the anti-PTPMEG immunoprecipitate (Fig. 6f). Therefore, PTPMEG interacts with GluN2A and GluN2B and most likely regulates Tyr phosphorylation of both subunits in the hippocampus. Tyr phosphorylation involving Tyr1472 in GluN2B and Tyr842 in GluN2A is known to regulate endocytosis and PSD abundance of both NMDAR subunits $[49,50]$. Unfortunately, there is no available antibody against phosphorylated GluN2A Tyr842, but it seems very likely that PTPMEG interaction with GluN2A subunit has also a functional consequence in the phosphorylation status of this residue.
Taken together, all these results support a role of NSPA as an E3 ubiquitin ligase and PTPMEG as one of its substrates that regulates NMDAR levels at the PSD. PTPMEG expression levels are controlled by the UPS and are sensitive to NSPA expression, impacting upon memory processes in the hippocampus.

\section{Discussion}

Since its discovery as a new neuronal surface protein [18], NSPA has been recognized as a mediator of the pathogenicity of anti-P autoantibodies that associate with psychosis and cognitive dysfunction in NPSLE $[1,2]$. Our previous studies placed glutamatergic synaptic plasticity at 

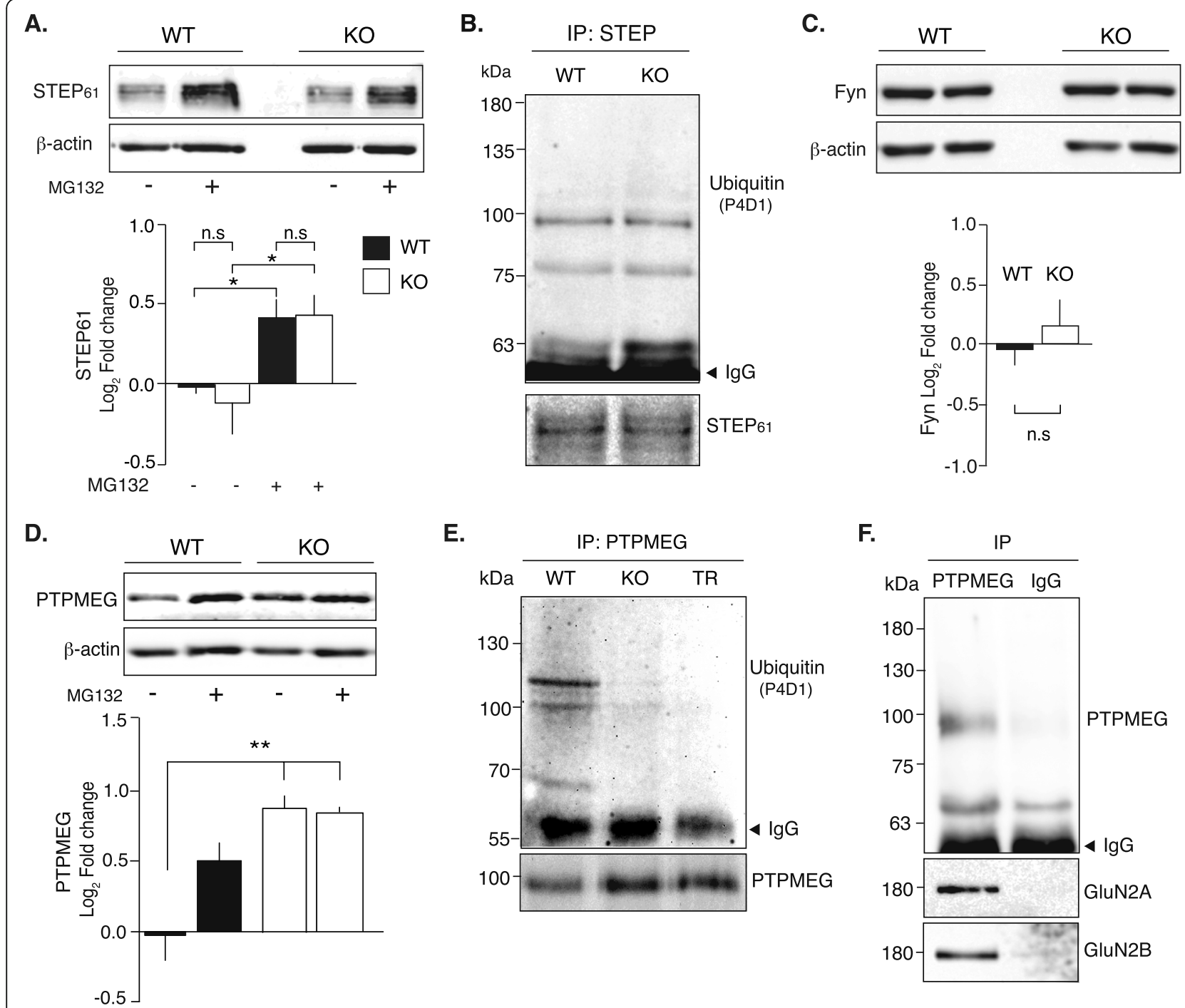

E.
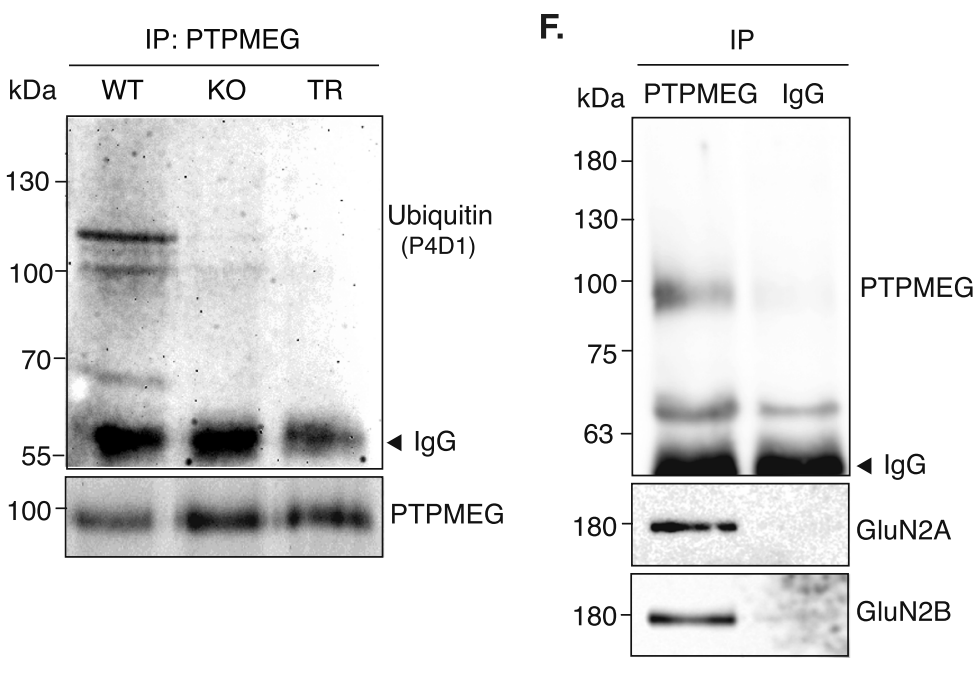

Fig. 6 PTPMEG levels are increased due to less ubiquitination in hippocampal fractions of NSPA-KO mice. a STEP 61 tyrosine phosphatase levels and $\mathbf{b}$ STEP 61 ubiquitination analysis show no differences in hippocampal P2 fractions from WT and NSPA-KO mice. MG-132 treatment equally increased STEP 61 levels in WT and NSPA-KO mice (mean \pm SEM; $n=4 ;{ }^{*} P<0.05 ; n . S$, non-statistical differences, $t$-test). c Fyn kinase immunoblot show similar band intensities in WT and NSPA-KO mice (mean $\pm \mathrm{SEM} ; n=3 ; n . s$, non-statistical differences in $t$-test). $\mathbf{d}$ The levels of PTPMEG are increased in NSPA-KO compared with WT hippocampal P2 fractions prepared with DMSO (vehicle), which instead become similar under MG-132 treatment (mean $\pm \mathrm{SEM} ; n=3$; **P $<0.01$, one-way ANOVA, followed Bonferroni's post hoc test). e NSPA-dependent ubiquitination of PTPMEG. Immunoprecipitated PTPMEG from hippocampal P2 fractions followed by immunoblot with anti-PTPMEG or anti-ubiquitin (P4D1) show ubiquitinated PTPMEG only in WT and not in NSPA-KO or NSPA-TR mice $(n=3)$. $\mathbf{f}$ GluN2A and GluN2B subunits co-immunoprecipitated with PTPMEG, as shown by immunoprecipitation with anti-PTPMEG or control lgG from WT P2 fractions followed by immunoblot with anti-GluN2A and anti-GluN2B antibodies. Source data values are included in Additional file 2

the center of NSPA-mediated anti-P alterations leading to memory impairments $[19,20]$. However, the mechanisms involving NSPA in synaptic function and memory processes remain little understood, limiting the possibility of targeted therapies against anti-P pathogenicity. The present study represents a significant step ahead. Our results obtained in NSPA-KO mouse and a heterologous cellular system point to NSPA as an E3 ubiquitin ligase involved in NMDAR expression at the PSD, which is indeed relevant in memory processes. PTPMEG qualifies as an NSPA-mediated ubiquitination substrate that is degraded by the UPS and very likely regulates NMDAR abundance at the PSD acting as a tyrosine phosphatase. We also found that NSPA is required for the process of adult neurogenesis, which depends on neuronal activity and can contribute to memory functions in the hippocampus [29, 36, 37]. These findings provide mechanistic basis for understanding the functional role of NSPA in neurons and as corollary suggest a pathway through which anti-P 
antibodies could drive neuronal dysfunctions and may be therapeutically targeted in NPSLE.

We first performed experiments similar to those previously reported in NSPA-TR mice using now a NSPA$\mathrm{KO}$ (Zzef1 ${ }^{\text {tm2.1(KOMP)vlcg }}$ ) mouse that completely lacks NSPA expression. NSPA-KO mice showed decreased synaptic plasticity in CA3-CA1 synapses and poor performance in memory flexibility. Therefore, our previous observations in NSPA-TR mice most likely resulted from defective NSPA function rather than a detrimental effect of the truncated protein. We extended the analysis and found that NSPA-KO mice also have an impaired LTP in MPP-DG synapses of dorsal hippocampus and performed poorly in object recognition tests, while open field assays did not detect anxiety-like behaviors. Object recognition tests not only reflect dysfunction in the hippocampus, as the memory flexibility test, but also in other brain regions such as the amygdala and cingulate cortex [51, 52], where NSPA is also expressed [18, 20]. All these results highlight a role of NSPA in glutamatergic synaptic plasticity associated with memory processes in the hippocampus and suggest other functional alterations remaining to be defined at different brain regions.

The impaired LTP in MPP-DG synapses of NSPA-KO mice led us to analyze neuronal activity at the DG and its related neurogenesis process. Neuronal activity promotes adult neurogenesis at the DG through secreted signaling factors that are sensed by neural progenitors $[53,54]$. The expression of Arc in glutamatergic neurons is highly sensitive to synaptic activity [33] and is required for LTP and memory performance [34, 35]. We found a decreased expression of Arc indicating lower activity of neurons that lack NSPA at the DG. LTP at MPP-DG has been shown to promote proliferation of NPCs in an NMDAR-dependent manner without affecting neuronal differentiation [30, 38, 55]. Accordingly, NSPA-KO neural progenitors in the SGZ of DG showed reduced neurogenesis associated with proliferation but not differentiation defects. These results indicate a requirement of NSPA in the proliferation activity of neural progenitors. However, because LTP promotes survival of adult-born neurons [30], and glutamatergic signaling through NMDAR is crucial for the survival and integration of newborn neurons [55], it is possible that survival deficits of newborn neurons might also occur in the absence of NSPA. Indeed, an impaired hippocampal neurogenesis, as a form of cellular plasticity involved in learning and memory $[29,36]$ whose reduction associates with LTP impairments, and vice versa $[38,56]$, very likely contributes to plasticity and cognitive dysfunction in NSPA-KO.

Next, we focused on the potential role of NSPA in ubiquitin-mediated processes that control NMDAR function. E3 ubiquitin ligases are classified in RING, HECT, and RBR major classes [57]. NSPA has a characteristic APC10 domain of E3 ubiquitin ligases and two ZZ-type zinc finger domains that may represent RING domains similar to those in RBR-type E3 ligases [20, 42]. Although RBR-type E3 ligases usually have a catalytic unit conformed by three RING domains, RING1, inbetween RING (BRcat or IBR), and RING2 (Rcat) [42, 57], some of these enzymes still promote ubiquitination when the RING1 domain is experimentally removed [58]. A biochemical hallmark of RBR-type E3 ligases is an active cysteine residue to which ubiquitin binds prior to its transfer to the substrate [42]. NSPA fulfill such criteria, as we demonstrated its ubiquitination in a cellbased assay. Further confirmation of NSPA as a member of the RBR E3 family would require defining whether conserved cysteines in ZZ-type domains are ubiquitinated. Nevertheless, structural and biochemical evidence, including the identification of an ubiquitination substrate, strongly suggest that NSPA might be the first transmembrane RBR-type E3 ubiquitin ligase.

NSPA function through ubiquitin-dependent pathways is an attractive possibility to explain why its absence leads to LTP impairment. Ubiquitination mediates protein degradation, signal transduction, and membrane trafficking associated with synapse maintenance, regulation, and organization in normal and altered brain functions [28]. Many proteins involved in synaptic plasticity are regulated by ubiquitination as specific substrates of particular E3 ubiquitin ligases [28]. The absence of NSPA as E3 ubiquitin ligase might result in higher levels of a substrate that is degraded by the UPS. We considered the cytosolic tyrosine phosphatase PTPMEG an interesting candidate. We found PTPMEG ubiquitinated in NSPA-WT but not in NSPA-KO mice, which accordingly showed increased PTPMEG levels in hippocampal fractions due to lower degradation by the UPS. Interaction between NSPA and PTPMEG is suggested by a wide-screen yeast two-hybrid analysis of braininteracting proteins [59]. PTPMEG then qualifies as a substrate of NSPA-mediated ubiquitination, providing a link with NMDAR functions controlled by tyrosine phosphorylation.

NMDAR presence at the cell surface, including the PSD, is mainly regulated by a tyrosine phosphorylation system so far attributed to the tyrosine kinase Fyn and phosphatase STEP $_{61}[9,11,45,46,49]$. The most studied example is GluN2B Tyr1472 that conforms to an endocytic signal. Tyr1472 phosphorylation prevents endocytosis and thus stabilizes the NMDAR at the PSD, whereas its dephosphorylation leads to an endocytic decrease of NMDAR levels at the PSD [9, 45]. Strikingly, NSPA-KO mice showed not only decreased levels of GluN2B subunit but also lower phosphorylation of 
GluN2B Tyr1472 at the hippocampal PSD. Neither STEP $_{61}$ nor Fyn showed evidence of changes congruent with a decreased GluN2B Tyr1472 phosphorylation. Instead, PTPMEG increased levels correlated well with the lower phosphorylated status of GluN2B Tyr1472. PTPMEG contains a PDZ (PSD95/Dlg/ZO-1) domain that interacts with proteins bearing a $\mathrm{C}$-terminal PDZligand sequence, including GluN2A and GluN2B [12, 14]. Our co-immunoprecipitation experiments corroborated that PTPMEG interacts with both GluN2A and GluN2B in the hippocampus. These assays cannot differentiate whether PTPMEG has a preference for either GluN2A or GluN2B subunits, as both can be found in the same tetrameric NMDAR [8]. Therefore, it seems very likely that PTPMEG dephosphorylates Tyr residues involved in endocytosis of both GluN2A and GluN2B subunits, with regulatory consequences upon the abundance of NMDAR at PSDs. Tyr phosphorylation status of GluN2A also regulates its cell surface stability [50], but there are no available antibodies against the endocytic-relevant phosphorylated Tyr in this subunit, as for GluN2B Tyr1472. However, we also found reduced GluN2A at the hippocampal PSD of NSPA-KO mice. All these data propose the following model. Increases in PTPMEG levels due to lower NSPAmediated ubiquitination promote Tyr dephosphorylation and then removal of both GluN2B and GluN2A from the PSD, with consequences in hippocampal LTP that would normally be initiated by NMDAR activation [4].

The few studies on PTPMEG in neurons have shown a role in cerebellar motor learning and LTD synaptic plasticity $[13,14]$. There are also two clinical cases of neurodevelopmental disorders seemingly involving hypofunctional PTPMEG [60, 61]. In one of these cases, a child with developmental delay, autistic features, and hypotonia was found to express a mutant PTPMEG that does not reach dendritic spines [61]. Our results are the first to evidence synaptic plasticity alterations associated with higher expression levels of PTPMEG in the hippocampus. The mechanism that regulates PTPMEG levels involves ubiquitination and degradation by the UPS, similar to other non-receptor tyrosine phosphatases [46, 62]. Interestingly, the unaffected PSD levels of PSD95 and AMPAR, whose degradation involves other ubiquitination systems [28], indicate a selectivity of the NSPA/PTPMEG pathway, so far including the NMDAR function.

Although we did not examine the NSPA/PTPMEG pathway directly in DG neural progenitors, NSPA and PTPMEG have been found to be expressed in DG $[12,20]$. If DG neural progenitors do not express these proteins, they would still be under the influence of mature neurons [53]. Therefore, the NSPA/PTPMEG pathway involved in NMDAR function might be expected to influence DG adult neurogenesis. As our KO mice constitutively lack NSPA expression, we cannot discard indirect contributions of embryological disturbances to the dysfunctions described here. Conditional/inducible knockout mouse technology would be necessary to further define the role of NSPA and PTPMEG in neurogenesis and memory processes.

How might these results help to understand and manage the pathogenic role of anti-P autoantibodies in NPSLE patients? NSPA is the only known target that mediates neuropathogenicity of anti-P antibodies in lupus patients [20]. In the last three decades, clinical associations of anti-P antibodies with different manifestations of NPSLE have been reported [63]. The demonstration of an anti-P cross-reacting protein such as NSPA in the surface of neurons [18], together with anti-P neuronal effects in the brain [18-20, 64-66], indeed give strong support to a neuropathogenic role of anti-P in NPSLE $[1,2,21]$. Circulating anti-P antibodies may exert neuronal alterations in the brain after $\mathrm{BBB}$ disruptions $[19,66]$, which frequently occur in SLE [67]. The association of circulating anti-P with lupus psychosis [68] has been well documented [69, 70]. Clinical [23] and experimental evidence [19, 20] also involve anti-P in CD, which is the most frequent NPSLE manifestation [2], independent of depression [71], and may contribute to reduce health-related quality of life in SLE patients [3]. Both psychotic and cognitive disorders involve alterations in glutamatergic receptors $[6,24,72]$ and can be elicited by a variety of different antibodies [21, 73]. Autoantibodies associated with autoimmune encephalitis can interfere with glutamatergic transmission directly targeting either NMDAR or AMPAR subunits, causing defective synaptic transmission and plasticity, memory dysfunction, and a diverse spectrum of neuropsychiatric manifestations [24]. The pathogenic mechanism of these antibodies often includes decreased location of NMDAR or AMPAR at the cell surface due to receptor internalization [24]. Similar anti-NMDAR antibodies that affect trafficking rather than channel activity have also been described in $20 \%$ of patients with psychosis due to schizophrenia [72]. In contrast, in patients with SLE, a subset of anti-double-stranded DNA antibodies that cross-react with NMDAR, originally described to bind GluN2A and GluN2B subunits in their open configuration [74], have more recently demonstrated preferential increase of synaptic transmission through GluN2A [25]. These lupus dsDNA/NMDAR antibodies also associate with spatial memory alterations and cognitive deficits in SLE patients [23, 75] and have the capability to alter spatial memory [76] and emotions [77] in mice, depending on where the BBB is breached. A long-term microglia-mediated damage also contributes to the pathogenesis of dsDNA/NMDAR antibodies [78]. In contrast with glutamatergic receptors as direct autoantibody targets, NSPA constitutes so far the only example of a target that mediates an antibody-driven 
indirect mechanism of NMDAR dysfunction. In mice, anti-P antibodies reproduce the phenotype of NSPA function absence leading to synaptic plasticity and memory impairments $[19,20]$, and also induce alterations of brain electrical activity likely eliciting glutamatergic dysfunctions [66]. Until now, empiric immunomodulatory therapy remains the main treatment for antibody-related neuropsychiatric disorders [2, 73]. However, improvements in understanding the pathogenic pathways of different antibodies are opening possibilities for evidencebased personalized and targeted therapies that are so far unavailable $[73,79]$. For instance, recent evidence in animal models suggests increasing the availability of NMDAR at the cell surface through Ephrin-B2 receptor activation in certain anti-NMDAR autoimmune encephalitis [73], while selective inhibition of GluN2A subunits [25] and microglia [78] would be more adequate in SLE patients bearing dsDNA/NMDAR antibodies. Our present results guarantee further studies to disclose how anti-P antibodies might disturb the role of NSPA/ PTPMEG/NMDAR pathway related with $C D$ and psychiatric disorders in SLE. Interestingly, anti-P antibodies can elicit calcium influx in neurons $[18,20]$, and calcium-regulated calpain acutely activates PTPMEG through proteolytic cleavage [80]. These antibodies might then induce trafficking alterations leading to NMDAR internalization. PTPMEG as a functional link between NSPA and NMDAR function and the requirement of NSPA in adult neurogenesis provide processes upon which anti-P effects and targeted therapeutic alternatives in NPSLE can be tested.

\section{Conclusions}

NSPA-dependent control of PTPMEG degradation involving ubiquitination provides a new pathway to be considered in processes of NMDAR-dependent synaptic plasticity and adult neurogenesis, as well as in the pathogenicity of anti-P autoantibodies in NPSLE. Previous studies have shown that autoantibodies directly targeting NMDAR and AMPAR are involved in neuropsychiatric manifestations of encephalitis syndromes [73], while a subset of anti-dsDNA antibodies cross-react with NMDAR and associate with CD in NPSLE [21, 22]. The NSPA/ PTPMEG pathway constitutes an additional target for antibodies that can alter glutamatergic transmission through a different mechanism. NSPA can potentially contribute to ubiquitination-mediated synaptic transmission regulation, which is known to include processes of protein degradation, signal transduction, and membrane trafficking, underlying normal brain functions and brain disorders [28]. Future studies exploring these possibilities would shed new light on the mechanisms of synaptic plasticity and adult neurogenesis, their relationships with antibody-driven brain dysfunctions, and their potential use as suitable therapeutic targets that are much needed in NPSLE.

\section{Methods \\ Antibodies}

Mouse antibodies from UC Davis/NIH/NeuroMab Facility (UCLA, Davis, CA, USA) include anti-GluN1 (N308/ 48) (Cat\#75-272, RRID:AB_11000180, 1:1000), antiGluN2A (N327/95) (Cat\#75-288, RRID:AB_2315842, 1: 500), anti-GluN2B (N59/36) (Cat\#75-101, RRID:AB 2232584, 1:1000), anti-GluA1 (N355/1) (Cat\#75-327, RRID:AB_2315840, 1:1000), anti-GluA2 (L21/32) (Cat\#75002, RRID:AB_2232661, 1:1000), and anti-PSD95 (K28/ 43) (Cat\#75-028, RRID:AB_2292909, 1:10,000), rabbit anti-phospho-GluN2B (Tyr1472) (Cell Signaling Technology Cat\#4208, RRID:AB_1549657, 1:1000), rabbit antiSynapsin I (Abcam Cat\#ab8, RRID:AB_2200097, 1:10, 000), mouse anti-Fyn (Santa Cruz Biotechnology Cat\#sc434, RRID:AB_627642, 1:1000), mouse anti-Src (17AT28) (Santa Cruz Biotechnology Cat\#sc-130124, RRID:AB 2196197, 1:500), mouse anti-STEP (clone 23E5) (Millipore Cat\#05-730, RRID:AB_11212456, 1:1000), rabbit antiPTPMEG (Allele Biotechnology Cat\# ABP-PAB-10818, 1: 1000), mouse anti-ubiquitin (P4D1) (Santa Cruz Biotechnology Cat\#sc-8017, RRID:AB_628423, 1:500), rabbit antiZZEF1 (Abcam Cat\#ab176594,1:2000), rat anti-BrdU BU1/75 (ICR1) (Abcam Cat\#ab6326, RRID:AB_305426, 1: 250), rabbit anti-mCherry (Abcam Cat\#ab167453, RRID: AB_2571870, 1:2500), rabbit anti-DCX (Cell Signaling Technology Cat\#4604, RRID:AB_561007, 1:500), mouse anti-NeuN (Millipore, Cat.\#MAB377, RRID:AB_2298772, 1:500), rabbit anti-Arc (Abcam Cat\#203056, RRID:AB_ 2827632, 1:100) and rabbit anti-Ki67 (Abcam Cat\#ab15580, RRID:AB_443209, 1:500), mouse antiGAPDH (Clone 6C5) (Millipore Cat\#CB1001, RRID:AB $2107426,1: 1000$ ), and mouse anti- $\beta$-actin (Abcam Cat\#ab6276, RRID:AB_2223210, 1:10000). Secondary antibodies include horseradish peroxidase (HRP)-conjugated antibodies (Rockland) for immunoblot and Alexa (Molecular Probes) and DyLight (Abcam) conjugated antibodies for immunofluorescence. Affinity-purified rabbit anti-APC10 (12000) has been previously reported [20].

\section{LacZ knockout mice, genotyping and NSPA expression} C57BL/6NTac Zzef1 ${ }^{\text {tm2.1(KOMP)vlcg }}$ (here called NSPAKO) mice were engineered in Regeneron Pharmaceuticals Inc., New York, using Velocigene technology [81], replacing the entire coding region of the mouse Zzef1 gene $(128 \mathrm{~kb})$ with ZEN-UB1 Cassette containing the LacZ gene that encodes $\beta$-galactosidase. Details are available at the Velocigene website (http://www.velocigene.com/ komp/detail/10007). The following primers used in RTPCR discarded NSPA mRNA expression: exons 4-5 (TATAGAAACGTCCTCCAACCC and GCTTCATCTT 
CAAACGTATCCA), exons 20-22 (GTCAACTGGT CATCTTCCTG and TCACACCTCTCATCAAATTC CA), exons 50-52 (TAGTGACTTTCAGCAGGACC and GATCTCAAACCCTGTCTGGA) for mice mRNA.

\section{Subcellular fractionation of mice hippocampi and immunoblotting}

Hippocampi of 2- to 4-month-old WT or NSPA-KO mice were dissected on ice and homogenized in homogenization buffer $(0.32 \mathrm{M}$ sucrose, $0.5 \mathrm{mM}$ EGTA, $5 \mathrm{mM}$ Hepes, pH 7.4) supplemented with $4 \mu \mathrm{g} / \mathrm{ml} \mathrm{leu-}$ peptin, $4 \mathrm{mM}$ PMSF, $4 \mu \mathrm{g} / \mathrm{ml}$ pepstatin, $25 \mathrm{mM} \mathrm{NaF}$, and $100 \mathrm{mM} \mathrm{Na}_{3} \mathrm{VO}_{4}$ using a Potter homogenizer. In the experiments that inhibit the proteasome activity, $25 \mu \mathrm{M}$ MG-132 or DMSO as control vehicle was additionally added. Homogenates were centrifuged twice at $1000 \times g$ for $10 \mathrm{~min}$ at $4{ }^{\circ} \mathrm{C}(\mathrm{H})$. The crude membrane fraction (P2) was obtained as described [82], centrifuging the supernatant $(\mathrm{S} 1)$ at $12,000 \times g$ for $20 \mathrm{~min}$ at $4{ }^{\circ} \mathrm{C}$. Synaptosomes were collected from the first sucrose step gradient at $1 / 1.2 \mathrm{M}$ interphase and submitted to hypo-osmotic shock to release intracellular organelles. To obtain PSDs, synaptic membranes were collected from a second sucrose gradient at the $1 / 1.2 \mathrm{M}$ interphase and delipidated in $320 \mathrm{mM}$ sucrose, $1 \mathrm{mM}$ dithiothreitol, $6 \mathrm{mM}$ Tris- $\mathrm{HCl}$ (pH 8.1), and $0.5 \%$ Triton X-100. Protein concentrations were determined using the BCA assay (Pierce, Thermo Fisher Scientific). Immunoblots were made as described [18].

\section{Immunoprecipitation}

P2 fractions from mice hippocampi solubilized in lysis buffer (50 mM Tris- $\mathrm{HCl}$ (pH 8.0), $150 \mathrm{mM} \mathrm{NaCl}, 2 \mathrm{mM}$ EDTA, 1\% Triton X-100) were subjected to immunoprecipitation with $1 \mu \mathrm{l}$ of PTPMEG antibody or $10 \mu \mathrm{l}$ of STEP antibody pre-bound to protein G-agarose; immunoprecipitated proteins were eluted with SDS sample buffer for subsequent immunoblotting.

\section{Behavioral tests}

\section{Open field and novel object recognition}

All tasks were conducted in a behavioral suite. Trials were filmed and collected using a video tracking system coupled to Honestech TVR 2.5 program and analyzed offline in ANY-MAZE software (Stoelting Co, Wood Dale, IL, USA). Two- to 3-month-old male mice were used for behavioral tests. WT and NSPA-KO mice were placed in the center of a $40 \times 40 \times 40 \mathrm{~cm}$ box and allowed to explore for $10 \mathrm{~min}$ to assess their horizontal locomotion, with the center zone line at $10 \mathrm{~cm}$ from the edge (used for open field analyses) [39]. According to a reported test [40], there was another 10-min habituation to acclimatize the mice to the novel object recognition (NOR) field. On the next day, a 10-min familiarization phase (Sample) was conducted (two of object A). One of the objects was then replaced $4 \mathrm{~h}$ later (delay) with a novel one, and a testing period (choice) was conducted (one of object A and object B). Mice were allowed to explore freely during $10 \mathrm{~min}$, object exploration was defined when a mouse directed its nose at an object within $\sim 2 \mathrm{~cm}$ or less and was actively investigating the object. For NOR, the "preference index" was calculated by the time spent to explore object $\mathrm{A}$ in the familiarization phase, or object $B$ in the testing phase, compared to the total time explored in both objects.

\section{Memory flexibility test}

A modification of Morris water maze protocol [41] was used as described [20], in which learning criteria is to find a submerged platform with a new location each day in less than $60 \mathrm{~s}$ (escape latency) on 3 successive attempts, without overpassing 15 trials per day.

\section{BrdU administration and immunofluorescence}

To analyze adult neurogenesis, 5-bromo-2'-deoxyuridine (BrdU, Sigma) was injected intraperitoneally $(100 \mathrm{mg} / \mathrm{kg})$ to 8 weeks mice for 3 days. Fourteen days after the last injection, mice were perfused with $4 \%$ paraformaldehyde and fixed brain sections were analyzed for BrdU and a neuronal marker immunofluorescence, as described [83]. BrdU-, Ki67-, or DCX-positive cells were counted using a fluorescence microscope (Olympus BX51, Tokyo, Japan) [83]. Double-labeled sections were analyzed by confocal laser microscopy (Leica SP8). Image analyses of maximal zprojections were made with Image software (NIH, USA).

\section{Electrophysiology}

Field excitatory postsynaptic potential (fEPSP)

Transverse slices $(400 \mu \mathrm{m})$ from the dorsal hippocampus of 2- to 3-month-old male mice were prepared, maintained, and processed for electrophysiology adding picrotoxin (PTX; $10 \mu \mathrm{M})$ to suppress inhibitory GABA transmission [20]. Recordings were filtered at $2.0-3.0 \mathrm{kHz}$, sampled at $4.0 \mathrm{kHz}$ using an A/D converter (National Instrument, Austin, TX, USA), and stored with the WinLTP program. To generate LTP in CA3-CA1 synapses, high-frequency stimulation (HFS) was used, consisting on 2 trains of 100 pulses at 100 $\mathrm{Hz}$ of stimuli, with an inter-train interval of $10 \mathrm{~s}$ [84]. LTP in MPP-DG synapses was induced by 4 trains of highfrequency stimulation at $100 \mathrm{~Hz}, 1 \mathrm{~s}$ in duration and $200 \mu \mathrm{s}$ pulse width, with 5-min interval [85]. Data were collected and analyzed offline with pClamp 10 (Molecular Devices, San Jose, CA, USA).

\section{Cell-based ubiquitination}

HEK293 cells co-transfected with NSPA-mCherry and myc-6xHis-ubiquitin for $24 \mathrm{~h}$ were subjected to Hisubiquitin-based assay as described [86], with minor 
modifications. Briefly, cells were lysed in buffer A2 (6M guanidine chloride, $0.1 \mathrm{M} \mathrm{Na} 2 \mathrm{HPO} 4 / \mathrm{NaH} 2 \mathrm{PO} 4$, and 10 $\mathrm{mM}$ immidazole, $\mathrm{pH}$ 8.0) and incubated with $100 \mu \mathrm{l}$ of Ni-NTA agarose (QIAGEN, Valencia/CA, www.qiagen. com) for $3 \mathrm{~h}$ at room temperature. Ni-NTA beads were washed twice with buffer A2 and buffer A2/TI (1 volume of buffer A2 and 3 volumes of buffer TI) and once with buffer TI ( $25 \mathrm{mM}$ Tris- $\mathrm{HCl}, 20 \mathrm{mM}$ imidazole, $\mathrm{pH}$ 6.8). Proteins eluted with buffer ETI $(50 \mathrm{mM}$ Tris- $\mathrm{HCl}, 20$ $\mathrm{mM}$ imidazole, $\mathrm{pH}$ 6.8) were analyzed by SDS-PAGE and immunoblotted with anti-mCherry antibodies.

\section{Statistical analysis}

The software GraphPad PRISM Version 6.0c (San Diego, CA) was used for statistical analysis. Data are presented as mean \pm SEM values and differences were analyzed with Student's $t$ test, Mann-Whitney, or one-way ANOVA followed by Bonferronni, as indicated. Statistical significances correspond to ${ }^{*} P<0.05,{ }^{* *} P<0.01$, ***:P$<0.001$, and ${ }^{* * * *} P<0.0001$.

\section{Supplementary information}

Supplementary information accompanies this paper at https://doi.org/10. 1186/s12915-020-00877-2.

Additional File 1: Figure S1. NSPA knockout mice (NSPA-KO). a Coronal slices of dorsal hippocampus from heterozygous NSPA-WT/KO mice stained for cresyl violet and $\beta$-Gal revealing activity of the NSPA promoter in CA1 and DG of the hippocampus. b Diagram of Zzef1 gene showing the location of primers for RT-PCR spanning different exons (4-5, 20-22 and 50-52 exons) and the EF-Hand (amino acids 94-141), APC10 (251-380) and ZZ (1781-1828 and 1830-1877) domains. c Lack of NSPA expression in NSPA-KO mice demonstrated by RT-PCR in hippocampal mRNA extracts and immunoblot with anti-APC10 and anti-ZZEF1 antibodies in P2 synaptosomal fractions (Arrows indicates NSPA band). Figure S2. Purity of isolated hippocampal postsynaptic densities (PSDs). Presynaptic marker VGlut1 and postsynaptic marker PSD95 were used to verify the purity of PSDs by western blot. Crude hippocampal extract $(H)$, supernatant obtained from hippocampal extract centrifugation (S2), crude membrane fraction (P2), synaptic membranes (SPM) and postsynaptic densities (PSD). Figure S3. Decreased levels of NMDAR GluN2A and GluN2B subunits in hippocampal synaptosomes of NSPA-KO mice. Hippocampal synaptosomes from WT and NSPA-KO mice were analyzed by immunoblot. Graph represents the intensity of the indicated proteins relative to beta-actin and shows significantly lower GluN2A and GluN2B levels in NSPA-KO compared with WT mice, while the levels of other proteins remain unaffected (mean \pm SEM; $n=6$ per group; ${ }^{*} P<0.05$, ${ }^{* *} P<$ $0.01, t$-test). Figure $\mathbf{S 4}$. Src kinase immunoblot show similar band intensities in WT and NSPA-KO mice (mean \pm SEM; $n=4 ; n . s$, non-statistical differences, $t$-test). Hippocampal P2 fractions from WT and NSPA-KO mice were analyzed by immunoblot. Source data values are included in Additional file 2

Additional file 2. Excel sheet containing source data file for Fig. 1e, 2c, d, 5a, b, 6a, c, d and Additional file 1: Fig. S4.

\section{Abbreviations}

AMPAR: a-Amino-3-hydroxy-5-methyl-4-isoxazolepropionic acid receptor; BBB: Blood-brain barrier; DG: Dentate gyrus; DCX: Doublecortin; fEPSP: Field excitatory postsynaptic potentials; LTP: Long-term potentiation; MPP: Medial perforant pathway; NMDAR: $N$-methyl-D-aspartate receptor; NOR: Novel object recognition; NPSLE: Neuropsychiatric systemic lupus erythematosus; NSPA: Neuronal surface P antigen; OF: Open field; PSD: Postsynaptic density; PTPMEG: Megakaryocyte protein tyrosine phosphatase; SGZ: Subgranular zone; STEP: Striatal-enriched protein tyrosine phosphatase; SLE: Systemic lupus erythematosus; UPS: Ubiquitin-proteasome system

\section{Acknowledgements}

The authors acknowledge the services provided by UC CINBIOT Animal Facility funded by PIA CONICYT Program for Associative Research, of the Chilean National Council for Science and Technology ECM-07.

\section{Authors' contributions}

S.E., W.C., L.V.N, and A.G. designed the research; S.E., S.B.A., F.B., F.C., F.G.G., and F.S.M. performed the experiments; D.M.V., U.W., and A.R.F. contributed with reagents and analytical tools; S.E., S.B.A., F.C., and F.S.M. analyzed the data; S.E., F.B., L.M., L.V.N., and A.G. wrote the paper. All authors read and approved the final manuscript.

\section{Funding}

This work received financial support from the Comisión Nacional de Investigación Científica y Tecnológica (CONICYT) "Programa de Apoyo a Centros con Financiamiento Basal" AFB170005 to the Center for Aging and Regeneration (CARE) (A.G. and W.C.) and AFB170004 to Fundación Ciencia \& Vida (A.G. and F.B.); Fondo Nacional de Desarrollo Científico y Tecnológico (Fondecyt) grant No1160513 (L.M.), Fondecyt grant No1190620, Sociedad Química y Minera de Chile (SQM) for special grant "the role of lithium in human health and disease"; BMBF 20150065 (PCI) (W.C.); Fondecyt grant No1190461 (L.V.N.); Fondecyt grant No1140108 (U.W.); and FONDEF IdeA ID17I10037 (A.R.F). Doctoral fellowships from CONICYT (S.E., F.C., S.B.A. and F.B.).

\section{Availability of data and materials}

All data generated or analyzed during this study are included in this published article and its supplementary information files.

\section{Ethics approval and consent to participate}

All protocols involving rodents were approved by the Ethical Scientific Committee of Universidad San Sebastián.

\section{Consent for publication}

Not applicable.

\section{Competing interests}

The authors report no competing interests.

\section{Author details}

${ }^{1}$ Centro de Biología Celular y Biomedicina (CEBICEM), Facultad de Medicina y Ciencia, Universidad San Sebastián, 7510157 Santiago, Chile. ${ }^{2}$ Centro de Envejecimiento y Regeneración (CARE), Facultad de Ciencias Biológicas, Pontificia Universidad Católica de Chile, 8330025 Santiago, Chile. ${ }^{3}$ Institute of Biomedical Sciences (ICB), Faculty of Medicine and Faculty of Life Sciences, Universidad Andrés Bello, 8370146 Santiago, Chile. ${ }^{4}$ Fundación Ciencia y Vida, 7780272 Santiago, Chile. ${ }^{5}$ Laboratorio de Función y Patología Neuronal, Departamento de Biología Celular y Molecular, Facultad de Ciencias Biológicas, Pontificia Universidad Católica de Chile, 8330028 Santiago, Chile. ${ }^{6}$ Centro de Excelencia en Biomedicina de Magallanes (CEBIMA), 6213029 Punta Arenas, Chile. ${ }^{7}$ Regeneron Pharmaceuticals, Inc., Tarrytown 10591, NY, USA. ${ }^{8}$ Laboratorio de Neurociencias, Facultad de Medicina, Universidad de los Andes, 7620001 Santiago, Chile. ${ }^{9}$ Center for Interdisciplinary Studies of the Nervous System (CISNe), Universidad Austral de Chile, 5090000 Valdivia, Chile.

Received: 30 March 2020 Accepted: 23 September 2020

Published online: 06 November 2020

\section{References}

1. Gonzalez A, Massardo L. Antibodies and the brain: antiribosomal P protein antibody and the clinical effects in patients with systemic lupus erythematosus. Curr Opin Neurol. 2018;31(3):300-5.

2. Schwartz N, Stock AD, Putterman C. Neuropsychiatric lupus: new mechanistic insights and future treatment directions. Nat Rev Rheumatol. 2019;15(3):137-52

3. Calderon J, Flores P, Aguirre JM, Valdivia G, Padilla O, Barra I, Scoriels L, Herrera S, Gonzalez A, Massardo L. Impact of cognitive impairment, depression, disease 
activity, and disease damage on quality of life in women with systemic lupus erythematosus. Scand J Rheumatol. 2017;46(4):273-80.

4. Malenka RC, Bear MF. LTP and LTD: an embarrassment of riches. Neuron. 2004:44(1):5-21.

5. Rao VR, Finkbeiner S. NMDA and AMPA receptors: old channels, new tricks. Trends Neurosci. 2007;30(6):284-91.

6. Citri A, Malenka RC. Synaptic plasticity: multiple forms, functions, and mechanisms. Neuropsychopharmacology. 2008;33(1):18-41.

7. Kessels HW, Malinow R. Synaptic AMPA receptor plasticity and behavior. Neuron. 2009;61(3):340-50.

8. Paoletti P, Bellone C, Zhou Q. NMDA receptor subunit diversity: impact on receptor properties, synaptic plasticity and disease. Nat Rev Neurosci. 2013; 14(6):383-400.

9. Prybylowski K, Chang K, Sans N, Kan L, Vicini S, Wenthold RJ. The synaptic localization of NR2B-containing NMDA receptors is controlled by interactions with PDZ proteins and AP-2. Neuron. 2005;47(6):845-57.

10. Goebel-Goody SM, Davies KD, Alvestad Linger RM, Freund RK, Browning MD. Phospho-regulation of synaptic and extrasynaptic N-methyl-d-aspartate receptors in adult hippocampal slices. Neuroscience. 2009;158(4):1446-59.

11. Kurup P, Zhang Y, Xu J, Venkitaramani DV, Haroutunian V, Greengard P, Nairn AC, Lombroso PJ. Abeta-mediated NMDA receptor endocytosis in Alzheimer's disease involves ubiquitination of the tyrosine phosphatase STEP61. J Neurosci. 2010;30(17):5948-57.

12. Hironaka K, Umemori H, Tezuka T, Mishina M, Yamamoto T. The proteintyrosine phosphatase PTPMEG interacts with glutamate receptor delta 2 and epsilon subunits. J Biol Chem. 2000;275(21):16167-73.

13. Kina S, Tezuka T, Kusakawa S, Kishimoto Y, Kakizawa S, Hashimoto K, Ohsugi M, Kiyama Y, Horai R, Sudo K, et al. Involvement of protein-tyrosine phosphatase PTPMEG in motor learning and cerebellar long-term depression. Eur J Neurosci. 2007;26(8):2269-78.

14. Kohda K, Kakegawa W, Matsuda S, Yamamoto T, Hirano H, Yuzaki M. The delta2 glutamate receptor gates long-term depression by coordinating interactions between two AMPA receptor phosphorylation sites. Proc Natl Acad Sci U S A. 2013;110(10):E948-57.

15. Jang SS, Royston SE, Xu J, Cavaretta JP, Vest MO, Lee KY, Lee S, Jeong HG, Lombroso PJ, Chung HJ. Regulation of STEP61 and tyrosine-phosphorylation of NMDA and AMPA receptors during homeostatic synaptic plasticity. Mol Brain. 2015;8(1):55

16. Gotz M, Nakafuku M, Petrik D: Neurogenesis in the developing and adult brain-similarities and key differences. Cold Spring Harb Perspect Biol. https:// doi.org/10.1101/cshperspect.a018853.

17. Cope EC, Gould E. Adult neurogenesis, glia, and the extracellular matrix. Cell Stem Cell. 2019;24(5):690-705.

18. Matus S, Burgos PV, Bravo-Zehnder M, Kraft R, Porras OH, Farias P, Barros LF, Torrealba F, Massardo L, Jacobelli S, et al. Antiribosomal-P autoantibodies from psychiatric lupus target a novel neuronal surface protein causing calcium influx and apoptosis. J Exp Med. 2007;204(13):3221-34.

19. Bravo-Zehnder M, Toledo EM, Segovia-Miranda F, Serrano FG, Benito MJ, Metz C, Retamal C, Alvarez A, Massardo L, Inestrosa NC, et al. Anti-ribosomal $P$ protein autoantibodies from patients with neuropsychiatric lupus impair memory in mice. Arthritis \& Rheumatology. 2015;67(1):204-14.

20. Segovia-Miranda F, Serrano F, Dyrda A, Ampuero E, Retamal C, BravoZehnder M, Parodi J, Zamorano P, Valenzuela D, Massardo L, et al. Pathogenicity of lupus anti-ribosomal $p$ antibodies: role of cross-reacting neuronal surface $p$ antigen in glutamatergic transmission and plasticity in a mouse model. Arthritis Rheumatol. 2015;67(6):1598-610.

21. Diamond B, Honig G, Mader S, Brimberg L, Volpe BT. Brain-reactive antibodies and disease. Annu Rev Immunol. 2013;31:345-85.

22. Mackay M, Vo A, Tang CC, Small M, Anderson EW, Ploran EJ, Storbeck J, Bascetta B, Kang S, Aranow C et al: Metabolic and microstructural alterations in the SLE brain correlate with cognitive impairment. JCI Insight. 2019;4(1): e124002. https://doi.org/10.1172/jci.insight.124002.

23. Massardo L, Bravo-Zehnder M, Calderon J, Flores P, Padilla O, Aguirre JM, Scoriels L, Gonzalez A. Anti-N-methyl-D-aspartate receptor and antiribosomal-P autoantibodies contribute to cognitive dysfunction in systemic lupus erythematosus. Lupus. 2015;24(6):558-68.

24. Dalmau J, Geis C, Graus F. Autoantibodies to synaptic receptors and neuronal cell surface proteins in autoimmune diseases of the central nervous system. Physiol Rev. 2017;97(2):839-87.

25. Chan K, Nestor J, Huerta TS, Certain N, Moody G, Kowal C, Huerta PT, Volpe BT, Diamond B, Wollmuth LP. Lupus autoantibodies act as positive allosteric modulators at GluN2A-containing NMDA receptors and impair spatial memory. Nat Commun. 2020;11(1):1403.

26. Boratyn GM, Schaffer AA, Agarwala R, Altschul SF, Lipman DJ, Madden TL. Domain enhanced lookup time accelerated BLAST. Biol Direct. 2012;7(1):12.

27. Kaustov L, Lukin J, Lemak A, Duan S, Ho M, Doherty R, Penn LZ, Arrowsmith $\mathrm{CH}$. The conserved $\mathrm{CPH}$ domains of Cul7 and PARC are protein-protein interaction modules that bind the tetramerization domain of p53. J Biol Chem. 2007;282(15):11300-7.

28. Mabb AM, Ehlers MD. Ubiquitination in postsynaptic function and plasticity. Annu Rev Cell Dev Biol. 2010;26:179-210.

29. Anacker C, Hen R. Adult hippocampal neurogenesis and cognitive flexibility - linking memory and mood. Nat Rev Neurosci. 2017;18(6):335-46.

30. Bruel-Jungerman E, Davis S, Rampon C, Laroche S. Long-term potentiation enhances neurogenesis in the adult dentate gyrus. J Neurosci. 2006;26(22): 5888-93.

31. Hainmueller T, Bartos M. Parallel emergence of stable and dynamic memory engrams in the hippocampus. Nature. 2018;558(7709):292-6.

32. Steward O, Wallace CS, Lyford GL, Worley PF. Synaptic activation causes the mRNA for the IEG arc to localize selectively near activated postsynaptic sites on dendrites. Neuron. 1998;21(4):741-51.

33. Ramirez-Amaya V, Vazdarjanova A, Mikhael D, Rosi S, Worley PF, Barnes CA. Spatial exploration-induced Arc mRNA and protein expression: evidence for selective, network-specific reactivation. J Neurosci. 2005;25(7):1761-8.

34. Guzowski JF, Lyford GL, Stevenson GD, Houston FP, McGaugh JL, Worley PF, Barnes CA. Inhibition of activity-dependent arc protein expression in the rat hippocampus impairs the maintenance of long-term potentiation and the consolidation of long-term memory. J Neurosci. 2000;20(11):3993-4001.

35. McIntyre CK, Miyashita T, Setlow B, Marjon KD, Steward O, Guzowski JF, McGaugh JL. Memory-influencing intra-basolateral amygdala drug infusions modulate expression of arc protein in the hippocampus. Proc Natl Acad Sci U S A. 2005;102(30):10718-23.

36. Goncalves JT, Schafer ST, Gage FH. Adult neurogenesis in the hippocampus: from stem cells to behavior. Cell. 2016;167(4):897-914.

37. Toni N, Schinder AF. Maturation and functional integration of new granule cells into the adult hippocampus. Cold Spring Harb Perspect Biol. 2015;8(1): a018903.

38. Chun SK, Sun W, Park JJ, Jung MW. Enhanced proliferation of progenitor cells following long-term potentiation induction in the rat dentate gyrus. Neurobiol Learn Mem. 2006;86(3):322-9.

39. Carola V, D'Olimpio F, Brunamonti E, Mangia F, Renzi P. Evaluation of the elevated plus-maze and open-field tests for the assessment of anxietyrelated behaviour in inbred mice. Behav Brain Res. 2002;134:49-57.

40. Cohen SJ, Munchow AH, Rios LM, Zhang G, Asgeirsdottir HN, Stackman RW $J$ r. The rodent hippocampus is essential for nonspatial object memory. Curr Biol. 2013;23(17):1685-90.

41. Chen G, Chen KS, Knox J, Inglis J, Bernard A, Martin SJ, Justice A, McConlogue L, Games D, Freedman SB, et al. A learning deficit related to age and beta-amyloid plaques in a mouse model of Alzheimer's disease. Nature. 2000;408(6815):975-9.

42. Spratt DE, Walden H, Shaw GS. RBR E3 ubiquitin ligases: new structures, new insights, new questions. Biochem J. 2014;458(3):421-37.

43. Wenzel DM, Lissounov A, Brzovic PS, Klevit RE. UBCH7 reactivity profile reveals parkin and HHARI to be RING/HECT hybrids. Nature. 2011;474(7349):105-8.

44. Lussier MP, Sanz-Clemente A, Roche KW. Dynamic regulation of N-methyl-daspartate (NMDA) and alpha-amino-3-hydroxy-5-methyl-4isoxazolepropionic acid (AMPA) receptors by posttranslational modifications. J Biol Chem. 2015;290(48):28596-603.

45. Xu F, Plummer MR, Len GW, Nakazawa T, Yamamoto T, Black IB, Wu K: Brain-derived neurotrophic factor rapidly increases NMDA receptor channel activity through Fyn-mediated phosphorylation. Brain Res 2006, 1121(1):22-34.

46. Won S, Incontro S, Nicoll RA, Roche KW. PSD-95 stabilizes NMDA receptors by inducing the degradation of STEP61. Proc Natl Acad Sci U S A. 2016; 113(32):E4736-44.

47. Kurup PK, Xu J, Videira RA, Ononenyi C, Baltazar G, Lombroso PJ, Nairn AC. STEP61 is a substrate of the E3 ligase parkin and is upregulated in Parkinson's disease. Proc Natl Acad Sci U S A. 2015;112(4):1202-7.

48. Xu J, Kurup P, Nairn AC, Lombroso PJ. Synaptic NMDA receptor activation induces Ubiquitination and degradation of STEP61. Mol Neurobiol.2017; 55(4):3096-111. https://doi.org/10.1007/s12035-017-0555-x.

49. Trepanier $\mathrm{CH}$, Jackson MF, MacDonald JF. Regulation of NMDA receptors by the tyrosine kinase Fyn. FEBS J. 2012;279(1):12-9. 
50. Vissel B, Krupp JJ, Heinemann SF, Westbrook GL. A use-dependent tyrosine dephosphorylation of NMDA receptors is independent of ion flux. Nat Neurosci. 2001;4(6):587-96.

51. Barsegyan A, Mirone G, Ronzoni G, Guo C, Song Q, van Kuppeveld D, Schut EHS, Atsak P, Teurlings S, McGaugh JL, et al. Glucocorticoid enhancement of recognition memory via basolateral amygdala-driven facilitation of prelimbic cortex interactions. Proc Natl Acad Sci U S A. 2019;116(14):7077-82.

52. Pezze MA, Marshall HJ, Fone KC, Cassaday HJ. Role of the anterior cingulate cortex in the retrieval of novel object recognition memory after a long delay. Learn Mem. 2017;24(7):310-7.

53. Ma DK, Jang MH, Guo JU, Kitabatake Y, Chang ML, Pow-Anpongkul N, Flavell RA, Lu B, Ming GL, Song H. Neuronal activity-induced Gadd45b promotes epigenetic DNA demethylation and adult neurogenesis. Science. 2009;323(5917):1074-7.

54. Jang MH, Bonaguidi MA, Kitabatake Y, Sun J, Song J, Kang E, Jun H, Zhong C, Su Y, Guo JU, et al. Secreted frizzled-related protein 3 regulates activitydependent adult hippocampal neurogenesis. Cell Stem Cell. 2013;12(2):215-23.

55. Tashiro A, Sandler VM, Toni N, Zhao C, Gage FH. NMDA-receptor-mediated, cell-specific integration of new neurons in adult dentate gyrus. Nature. 2006:442(7105):929-33.

56. Massa F, Koehl M, Wiesner T, Grosjean N, Revest J-M, Piazza P-V, Nora Abrous D, Oliet SHR. Conditional reduction of adult neurogenesis impairs bidirectional hippocampal synaptic plasticity. Proc Natl Acad Sci. 2011; 108(19):8065.

57. Zheng N, Shabek N. Ubiquitin ligases: structure, function, and regulation. Annu Rev Biochem. 2017;86:129-57.

58. Chew KC, Matsuda N, Saisho K, Lim GG, Chai C, Tan HM, Tanaka K, Lim KL. Parkin mediates apparent E2-independent monoubiquitination in vitro and contains an intrinsic activity that catalyzes polyubiquitination. PLoS One. 2011;6(5):e19720.

59. Stelzl U, Worm U, Lalowski M, Haenig C, Brembeck FH, Goehler H, Stroedicke M, Zenkner M, Schoenherr A, Koeppen S, et al. A human proteinprotein interaction network: a resource for annotating the proteome. Cell. 2005;122(6):957-68.

60. Williamson SL, Ellaway CJ, Peters GB, Pelka GJ, Tam PP, Christodoulou J. Deletion of protein tyrosine phosphatase, non-receptor type 4 (PTPN4) in twins with a Rett syndrome-like phenotype. Eur J Hum Genet. 2015;23(9): 1171-5.

61. Szczaluba K, Chmielewska JJ, Sokolowska O, Rydzanicz M, Szymanska K, Feleszko W, Wlodarski P, Biernacka A, Murcia Pienkowski V, Walczak A, et al. Neurodevelopmental phenotype caused by a de novo PTPN4 single nucleotide variant disrupting protein localization in neuronal dendritic spines. Clin Genet. 2018;94(6):581-5.

62. Jing M, Bohl J, Brimer N, Kinter M, Vande Pol SB. Degradation of tyrosine phosphatase PTPN3 (PTPH1) by association with oncogenic human papillomavirus E6 proteins. J Virol. 2007;81(5):2231-9.

63. Viana VT, Durcan L, Bonfa E, Elkon KB. Ribosomal $P$ antibody: 30 years on the road. Lupus. 2017;26(5):453-62.

64. Katzav A, Ben-Ziv T, Chapman J, Blank M, Reichlin M, Shoenfeld Y. Anti-P ribosomal antibodies induce defect in smell capability in a model of CNS -SLE (depression). J Autoimmun. 2008;31(4):393-8.

65. Gaburo N Jr, de Carvalho JF, Timo-laria CIM, Bueno C, Reichlin M, Viana VS, Bonfa E. Electrophysiological dysfunction induced by anti-ribosomal P protein antibodies injection into the lateral ventricle of the rat brain. Lupus. 2017;26(5):463-9.

66. Wang X, Li Y, Li Z, Li J, Xu J, Yang P, Qin L. Neuroprotective effect of microglia against impairments of auditory steady-state response induced by anti-P lgG from SLE patients in naive mice. J Neuroinflammation. 2020;17(1):31.

67. Stock AD, Gelb S, Pasternak O, Ben-Zvi A, Putterman C. The blood brain barrier and neuropsychiatric lupus: new perspectives in light of advances in understanding the neuroimmune interface. Autoimmun Rev. 2017;16(6): 612-9.

68. Bonfa E, Golombek SJ, Kaufman LD, Skelly S, Weissbach H, Brot N, Elkon KB. Association between lupus psychosis and anti-ribosomal $\mathrm{P}$ protein antibodies. N Engl J Med. 1987;317(5):265-71.

69. Bortoluzzi A, Scire CA, Bombardieri S, Caniatti L, Conti F, De Vita S, Doria A, Ferraccioli G, Gremese E, Mansutti E, et al. Development and validation of a new algorithm for attribution of neuropsychiatric events in systemic lupus erythematosus. Rheumatology (Oxford). 2015;54(5):891-8.

70. Sciascia S, Bertolaccini ML, Roccatello D, Khamashta MA, Sanna G Autoantibodies involved in neuropsychiatric manifestations associated with systemic lupus erythematosus: a systematic review. J Neurol. 2014;261(9): 1706-14.

71. Calderón J, Flores P, Babul M, Aguirre JM, Slachevski A, Padilla O, Scoriels L, Henríquez C, Cárcamo C, Bravo-Zenhder M et al: Systemic lupus erythematosus impairs memory cognitive tests not affected by depression. Lupus. 2014;23(10):1042-53. https://doi.org/10.1177/0961203314536247.

72. Jezequel J, Johansson EM, Dupuis JP, Rogemond V, Grea H, Kellermayer B, Hamdani N, Le Guen E, Rabu C, Lepleux M, et al. Dynamic disorganization of synaptic NMDA receptors triggered by autoantibodies from psychotic patients. Nat Commun. 2017;8(1):1791.

73. Dalmau J, Armangue T, Planaguma J, Radosevic M, Mannara F, Leypoldt F, Geis C, Lancaster E, Titulaer MJ, Rosenfeld MR, et al. An update on antiNMDA receptor encephalitis for neurologists and psychiatrists: mechanisms and models. Lancet Neurol. 2019;18(11):1045-57.

74. Faust TW, Chang EH, Kowal C, Berlin R, Gazaryan IG, Bertini E, Zhang J, Sanchez-Guerrero J, Fragoso-Loyo HE, Volpe BT, et al. Neurotoxic lupus autoantibodies alter brain function through two distinct mechanisms. Proc Natl Acad Sci U S A. 2010;107(43):18569-74.

75. Chang EH, Volpe BT, Mackay M, Aranow C, Watson P, Kowal C, Storbeck J, Mattis $P$, Berlin R, Chen H, et al. Selective impairment of spatial cognition caused by autoantibodies to the $\mathrm{N}$-methyl-D-aspartate receptor. EBioMedicine. 2015;2(7):755-64

76. Kowal C, Degiorgio LA, Lee JY, Edgar MA, Huerta PT, Volpe BT, Diamond B. Human lupus autoantibodies against NMDA receptors mediate cognitive impairment. Proc Natl Acad Sci U S A. 2006;103(52):19854-9.

77. Huerta PT, Kowal C, DeGiorgio LA, Volpe BT, Diamond B. Immunity and behavior: antibodies alter emotion. Proc Natl Acad Sci U S A. 2006;103(3): 678-83.

78. Nestor J, Arinuma Y, Huerta TS, Kowal C, Nasiri E, Kello N, Fujieda Y, Bialas A, Hammond T, Sriram U, et al. Lupus antibodies induce behavioral changes mediated by microglia and blocked by ACE inhibitors. J Exp Med. 2018; 215(10):2554-66.

79. Kello N, Anderson E, Diamond B. Cognitive dysfunction in systemic lupus erythematosus: a case for initiating trials. Arthritis Rheumatol. 2019;71(9): 1413-25.

80. Gu M, Majerus PW. The properties of the protein tyrosine phosphatase PTPMEG. J Biol Chem. 1996;271(44):27751-9.

81. Valenzuela DM, Murphy AJ, Frendewey D, Gale NW, Economides AN, Auerbach W, Poueymirou WT, Adams NC, Rojas J, Yasenchak J, et al. Highthroughput engineering of the mouse genome coupled with highresolution expression analysis. Nat Biotechnol. 2003;21(6):652-9.

82. Wyneken U, Smalla KH, Marengo JJ, Soto D, de la Cerda A, Tischmeyer W, Grimm R, Boeckers TM, Wolf G, Orrego F, et al. Kainate-induced seizures alter protein composition and $\mathrm{N}$-methyl-D-aspartate receptor function of rat forebrain postsynaptic densities. Neuroscience. 2001;102(1):65-74.

83. Abbott AC, Calderon Toledo C, Aranguiz FC, Inestrosa NC, Varela-Nallar L. Tetrahydrohyperforin increases adult hippocampal neurogenesis in wildtype and APPswe/PS1DeltaE9 mice. J Alzheimers Dis. 2013;34(4):873-85.

84. Carvajal FJ, Mira RG, Rovegno M, Minniti AN, Cerpa W: Age-related NMDA signaling alterations in SOD2 deficient mice. Biochimica et Biophysica Acta 2018, 1864(6 Pt A):2010-2020.

85. Schreurs A, Sabanov V, Balschun D. Distinct properties of long-term potentiation in the dentate gyrus along the dorsoventral axis: influence of age and inhibition. Sci Rep. 2017;7(1):5157.

86. Tatham MH, Rodriguez MS, Xirodimas DP, Hay RT. Detection of protein SUMOylation in vivo. Nat Protoc. 2009;4(9):1363-71.

\section{Publisher's Note}

Springer Nature remains neutral with regard to jurisdictional claims in published maps and institutional affiliations. 